\title{
Dramatic Increases in Obesity and Overweight Prevalence and Body Mass Index Among Ethnic-Immigrant and Social Class Groups in the United States, 1976-2008
}

\author{
Gopal K. Singh • Mohammad Siahpush • \\ Robert A. Hiatt $\cdot$ Lava R. Timsina
}

Published online: 12 June 2010

(C) The Author(s) 2010. This article is published with open access at Springerlink.com

\begin{abstract}
This study examined trends in US obesity and overweight prevalence and body mass index (BMI) among 30 immigrant groups, stratified by race/ethnicity and length of immigration, and among detailed education, occupation, and income/poverty groups from 1976 to 2008. Using 1976-2008 National Health Interview Surveys, differentials in obesity, overweight, and BMI, based on selfreported height and weight, were analyzed by using disparity indices, logistic, and linear regression. The obesity prevalence for the US population aged $\geq 18$ tripled from $8.7 \%$ in 1976 to $27.4 \%$ in 2008 . Overweight prevalence increased from $36.9 \%$ in 1976 to $62.0 \%$ in 2008. During 1991-2008, obesity prevalence for US-born adults increased from 13.9 to $28.7 \%$, while prevalence for immigrants increased from 9.5 to $20.7 \%$. While immigrants in each ethnic group and time period had lower obesity and
\end{abstract}

The views expressed are the authors' and not necessarily those of the Health Resources and Services Administration or the US Department of Health and Human Services.

G. K. Singh ( $₫)$

US Department of Health and Human Services, Health Resources and Services Administration, Maternal and Child Health Bureau, 5600 Fishers Lane, Room 18-41, Rockville, MD 20857, USA

e-mail: gsingh@hrsa.gov

\section{Siahpush · L. R. Timsina}

Department of Health Promotion, Social and Behavioral Health, College of Public Health, University of Nebraska Medical

Center, Omaha, NE 68198, USA

\section{R. A. Hiatt}

UCSF Helen Diller Family Comprehensive Cancer Center, Department of Epidemiology and Biostatistics, University of California at San Francisco, San Francisco, CA 94143-0560, USA overweight prevalence and BMI than the US-born, immigrants' risk of obesity and overweight increased with increasing duration of residence. In 2003-2008, obesity prevalence ranged from $2.3 \%$ for recent Chinese immigrants to 31-39\% for American Indians, US-born blacks, Mexicans, and Puerto Ricans, and long-term Mexican and Puerto Rican immigrants. Between 1976 and 2008, the obesity prevalence more than quadrupled for those with a college education or sales occupation. Although higher prevalence was observed for lower education, income, and occupation levels in each period, socioeconomic gradients in obesity and overweight decreased over time because of more rapid increases in prevalence among higher socioeconomic groups. Continued immigrant and socioeconomic disparities in prevalence will likely have substantial impacts on future obesity trends in the US.

Keywords Obesity - Overweight · Trend . Immigrant status - Ethnicity - Socioeconomic status . Acculturation - Disparities - Physical activity - Diet . United States

\section{Introduction}

The prevalence of obesity has risen dramatically in the United States. The rates for adults have more than doubled during the past 3 decades [1]. Increases in obesity prevalence have been marked across all gender, race, and socioeconomic groups [1]. Because of a relatively high prevalence, a rapidly increasing trend, and large socialgroup disparities, adult obesity is recognized as a major public health problem in the US [1,2].

While obesity data for US adults are routinely available by age, gender, and race/ethnicity [1,3], prevalence 
estimates for various immigrant and socioeconomic groups are less well known, particularly temporal obesity patterns among them [4-7]. The immigrant population in the US has increased four-fold in the last four decades [8-10]. In 2008, there were 38 million immigrants, an increase of 28.4 million since 1970 [8-10]. Immigrants currently account for $12.5 \%$ of the total US population [10].

Given such a rapid population increase, analysis of obesity patterns among immigrants of various ethnicities assumes a special importance [4, 11]. In addition to ethnic and immigrant disparities, monitoring socioeconomic inequalities in health has long represented an important research and policy focus $[1,2]$. Socioeconomic inequalities as well as immigrant differentials in health, life expectancy, and mortality from major causes of death have not only remained substantial in the US but have also increased over time [4, 12-15]. Inequalities in chronic disease risk factors such as obesity, smoking, physical inactivity, and poor diet have contributed greatly to the persistence and/or widening of the health gradients $[1,12,13,16]$. The purpose of this study was to describe national trends in immigrant and social class inequalities in the prevalence of obesity and overweight and to identify immigrant and social class groups who are at high risk of obesity and who have experienced substantial increases in their obesity rates. Specifically, we (1) estimate over time changes in obesity and overweight prevalence among 30 major immigrant groups stratified by race/ethnicity and length of immigration and among detailed education, occupation, and income groups, using large, nationally representative samples of US adults and (2) compare the magnitude of ethnic-immigrant and socioeconomic disparities in obesity and overweight prevalence among adults aged $\geq 18$ over time.

\section{Methods}

Temporal individual-level data on obesity, overweight, and selected socioeconomic, demographic, and behavioral characteristics were derived from the 1976 and 1991-2008 National Health Interview Surveys (NHIS) [17, 18]. The NHIS, which is conducted by the National Center for Health Statistics, uses a complex, multistage probability design and is representative of the civilian non-institutionalized population of the US [17, 18]. The household response rate for an annual NHIS generally exceeds $85 \%$. All data are based on self-reports, including height and weight information, and obtained via in-home person interviews [1, 17, 18]. Substantive and methodological details of the NHIS are described elsewhere [1, 17, 18].

Annual trends in obesity and overweight prevalence and BMI were estimated for the overall immigrant and US-born groups and for five educational groups from 1991 to 2008.
To analyze trends over time by detailed ethnic-immigrant and socioeconomic characteristics, we pooled 4 years of the NHIS data from 1992 to 1995 and 6 years of data from 2003 to 2008. Aggregating data for several years in this fashion ensured sufficient sample sizes for analyzing patterns for groups stratified by ethnicity, immigrant status, and length of immigration. We could not use the 1991 NHIS file in the pooled analyses because it lacked detailed ethnic and income groupings. The 1976 NHIS, the earliest survey to collect height and weight data, was used to provide baseline estimates for various socioeconomic groups. The 1976 NHIS did not include information on immigrant status.

Obesity and overweight differentials were analyzed for 323,627 adults in 1992-1995 and 154,649 adults aged $\geq 18$ in 2003-2008 for whom information on BMI was available. Adult overweight was defined as a BMI $\geq 25 \mathrm{~kg} / \mathrm{m}^{2}$ and obesity as a BMI $\geq 30 \mathrm{~kg} / \mathrm{m}^{2}[1,4,19]$. Note that the overweight category includes obese individuals.

Immigrant status was defined on the basis of adults' place of birth [4, 9, 11]. US-born were those born in one of the 50 US states or Washington, DC. Immigrants or foreign-born refer to those born outside these territories [4, 9, 11]. Race/ethnicity was classified into 11 major categories: non-Hispanic whites, non-Hispanic blacks, American Indians/Alaska Natives, Chinese, Asian Indians, Filipinos, other Asian/Pacific Islanders, Mexicans, Puerto Ricans, Cubans, and Central and South Americans, including other Hispanics. The joint variable of ethnicimmigrant status included 30 categories, with each racial/ ethnic group (except for American Indians/Alaska Natives who are, by definition, a native group) divided into the US-born group, the recent immigrant group, and the longterm immigrant group [9]. Although all Puerto Ricans are US citizens, those born in Puerto Rico and abroad were classified as "immigrants" for convenience. Following a previous study and given the health and socio-behavioral profiles by duration of residence, recent immigrants were defined as those who immigrated to the US in the previous 15 years, whereas long-term immigrants were those who immigrated to the US more than previous 15 years [9].

In addition to ethnic-immigrant status, we considered the following socioeconomic and demographic factors that are known to influence obesity: age, gender, marital status, region of residence, educational attainment, family income/ poverty status, occupation, and physical activity (PA) $[4,5$, 7, 11, 19]. These covariates were measured as shown in Tables 1 and 2 .

Educational attainment was measured both as a categorical variable $(0-8,9-11,12,13-15, \geq 16$ years $)$ and a continuous variable in terms of years of school completed. Annual family income was also measured both as a 
Table 1 Observed (weighted) prevalence and adjusted odds of obesity (BMI $\geq 30$ ) among 30 ethnic-immigrant groups aged $18+$ years and by selected socioeconomic and demographic characteristics: The National Health Interview Survey, 1992-2008

\begin{tabular}{|c|c|c|c|c|c|c|c|c|c|c|c|}
\hline \multirow[t]{3}{*}{ Covariates } & \multicolumn{5}{|c|}{$1992-1995(N=323,627)$} & \multicolumn{5}{|c|}{ 2003-2008 $(N=154,649)$} & \multirow{3}{*}{$\begin{array}{l}\text { 1992-2008 } \\
\% \text { Increase } \\
\text { in prevalence }\end{array}$} \\
\hline & \multicolumn{2}{|c|}{ Prevalence } & \multicolumn{3}{|c|}{ Adjusted odds ratio ${ }^{\mathrm{a}}$} & \multicolumn{2}{|c|}{ Prevalence } & \multicolumn{3}{|c|}{ Adjusted odds ratio ${ }^{a}$} & \\
\hline & $\%$ & SE & OR & $95 \%$ & & $\%$ & SE & OR & $95 \%$ & & \\
\hline \multicolumn{12}{|c|}{ Duration of residence in the US (years) } \\
\hline$<1$ & 5.7 & 0.8 & 0.41 & 0.30 & 0.55 & 8.1 & 1.5 & 0.27 & 0.18 & 0.41 & 44.1 \\
\hline $1-5$ & 7.9 & 0.5 & 0.53 & 0.46 & 0.61 & 10.8 & 0.7 & 0.35 & 0.29 & 0.40 & $36.0^{*}$ \\
\hline $5-9$ & 7.6 & 0.3 & 0.43 & 0.39 & 0.48 & 14.6 & 0.6 & 0.42 & 0.37 & 0.47 & $91.2 *$ \\
\hline $10-14$ & 9.7 & 0.4 & 0.57 & 0.52 & 0.63 & 16.4 & 0.8 & 0.47 & 0.42 & 0.53 & $68.4 *$ \\
\hline $15+$ & 13.1 & 0.3 & 0.72 & 0.68 & 0.76 & 22.0 & 0.4 & 0.66 & 0.62 & 0.70 & $67.9 *$ \\
\hline US-born & 15.6 & 0.1 & 1.00 & \multicolumn{2}{|c|}{ Reference } & 26.5 & 0.2 & 1.00 & \multicolumn{2}{|c|}{ Reference } & $70.6^{*}$ \\
\hline Relative index of disparity & 36.12 & 2.24 & & & & 38.15 & 2.23 & & & & 5.6 \\
\hline Gamma $(\gamma)$ & 0.18 & 0.008 & & & & 0.21 & 0.008 & & & & $16.7 *$ \\
\hline \multicolumn{12}{|l|}{ Non-Hispanic White } \\
\hline Recent immigrants ${ }^{\mathrm{b}}$ & 9.1 & 0.6 & 0.66 & 0.57 & 0.77 & 10.5 & 0.9 & 0.41 & 0.34 & 0.50 & 14.8 \\
\hline Long-term immigrants ${ }^{\mathrm{b}}$ & 11.3 & 0.4 & 0.74 & 0.68 & 0.80 & 19.2 & 0.9 & 0.75 & 0.67 & 0.83 & $69.6^{*}$ \\
\hline US-born & 14.2 & 0.1 & 1.00 & \multicolumn{2}{|c|}{ Reference } & 24.7 & 0.2 & 1.00 & \multicolumn{2}{|c|}{ Reference } & $73.3^{*}$ \\
\hline \multicolumn{12}{|l|}{ Non-Hispanic Black } \\
\hline Recent immigrants & 11.9 & 1.0 & 0.82 & 0.68 & 0.99 & 17.3 & 1.4 & 0.64 & 0.53 & 0.79 & $46.1 *$ \\
\hline Long-term immigrants & 13.8 & 1.1 & 0.88 & 0.72 & 1.08 & 25.7 & 1.8 & 0.95 & 0.79 & 1.14 & $86.9 *$ \\
\hline US-born & 23.9 & 0.3 & 1.71 & 1.65 & 1.77 & 36.1 & 0.4 & 1.60 & 1.53 & 1.67 & $51.2 *$ \\
\hline American Indian/Alaska Native & 22.4 & 1.4 & 1.58 & 1.32 & 1.88 & 39.2 & 2.1 & 1.81 & 1.51 & 2.17 & $75.2 *$ \\
\hline \multicolumn{12}{|l|}{ Chinese } \\
\hline Recent immigrants & 1.1 & 0.3 & 0.07 & 0.04 & 0.13 & 2.3 & 0.8 & 0.08 & 0.04 & 0.17 & 108.1 \\
\hline Long-term immigrants & 2.2 & 0.5 & 0.14 & 0.09 & 0.22 & 3.2 & 0.9 & 0.11 & 0.06 & 0.19 & 45.5 \\
\hline US-born & 5.9 & 1.6 & 0.54 & 0.32 & 0.91 & 8.4 & 2.1 & 0.40 & 0.23 & 0.67 & 43.4 \\
\hline \multicolumn{12}{|l|}{ Filipino } \\
\hline Recent immigrants & 2.1 & 0.5 & 0.15 & 0.09 & 0.24 & 7.6 & 1.9 & 0.29 & 0.18 & 0.48 & $256.5^{*}$ \\
\hline Long-term immigrants & 4.8 & 0.9 & 0.32 & 0.22 & 0.47 & 12.6 & 1.6 & 0.45 & 0.34 & 0.59 & $164.2 *$ \\
\hline US-born & 11.3 & 2.7 & 1.03 & 0.63 & 1.68 & 19.7 & 2.5 & 0.85 & 0.62 & 1.15 & $74.7 *$ \\
\hline \multicolumn{12}{|l|}{ Asian Indian } \\
\hline Recent immigrants & 3.3 & 0.7 & 0.23 & 0.15 & 0.35 & 5.7 & 1.0 & 0.23 & 0.16 & 0.33 & $75.7 *$ \\
\hline Long-term immigrant/US-born & 5.3 & 1.1 & 0.38 & 0.25 & 0.59 & 8.8 & 1.4 & 0.33 & 0.23 & 0.47 & 65.6 \\
\hline \multicolumn{12}{|l|}{ Other Asian and Pacific Islanders } \\
\hline Recent immigrants & 2.8 & 0.5 & 0.17 & 0.12 & 0.25 & 4.0 & 0.8 & 0.13 & 0.09 & 0.20 & 40.4 \\
\hline Long-term immigrants & 4.5 & 0.8 & 0.28 & 0.19 & 0.41 & 7.1 & 0.9 & 0.22 & 0.17 & 0.29 & $60.2 *$ \\
\hline US-born & 7.9 & 1.0 & 0.63 & 0.50 & 0.81 & 18.1 & 2.3 & 0.82 & 0.62 & 1.09 & $129.9 *$ \\
\hline Mexican & & & & & & & & & & & \\
\hline Recent immigrants & 12.8 & 0.7 & 0.75 & 0.67 & 0.84 & 18.9 & 0.7 & 0.66 & 0.59 & 0.74 & $47.9 *$ \\
\hline Long-term immigrants & 21.3 & 0.8 & 1.15 & 1.05 & 1.26 & 30.8 & 0.8 & 1.03 & 0.94 & 1.13 & $44.8^{*}$ \\
\hline US-born & 21.2 & 0.5 & 1.59 & 1.50 & 1.69 & 34.6 & 0.8 & 1.64 & 1.51 & 1.77 & $62.9 *$ \\
\hline Puerto Rican & & & & & & & & & & & \\
\hline Recent immigrants & 14.9 & 1.1 & 0.91 & 0.76 & 1.08 & 27.6 & 3.0 & 1.18 & 0.89 & 1.57 & $84.7 *$ \\
\hline Long-term immigrants & 22.4 & 1.2 & 1.22 & 1.07 & 1.40 & 32.7 & 1.7 & 1.23 & 1.06 & 1.44 & $46.2 *$ \\
\hline US-born & 14.2 & 0.8 & 1.10 & 0.96 & 1.27 & 30.6 & 1.5 & 1.32 & 1.15 & 1.51 & $116.2 *$ \\
\hline Cuban & & & & & & & & & & & \\
\hline Recent immigrants & 12.5 & 0.9 & 0.67 & 0.57 & 0.79 & 22.0 & 3.2 & 0.72 & 0.49 & 1.04 & $75.4^{*}$ \\
\hline Long-term immigrants & 16.0 & 2.3 & 0.98 & 0.71 & 1.37 & 24.2 & 1.8 & 0.84 & 0.69 & 1.01 & $50.7 *$ \\
\hline US-born & 14.1 & 0.1 & 1.16 & 0.88 & 1.53 & 24.1 & 2.9 & 1.13 & 0.82 & 1.55 & $71.3^{*}$ \\
\hline
\end{tabular}


Table 1 continued

\begin{tabular}{|c|c|c|c|c|c|c|c|c|c|c|c|}
\hline \multirow[t]{3}{*}{ Covariates } & \multicolumn{5}{|c|}{$1992-1995(N=323,627)$} & \multicolumn{5}{|c|}{ 2003-2008 $(N=154,649)$} & \multirow{3}{*}{$\begin{array}{l}\text { 1992-2008 } \\
\% \text { Increase } \\
\text { in prevalence }\end{array}$} \\
\hline & \multicolumn{2}{|c|}{ Prevalence } & \multicolumn{3}{|c|}{ Adjusted odds ratio ${ }^{a}$} & \multicolumn{2}{|c|}{ Prevalence } & \multicolumn{3}{|c|}{ Adjusted odds ratio ${ }^{a}$} & \\
\hline & $\%$ & SE & OR & $95 \%$ & & $\%$ & SE & OR & $95 \%$ & & \\
\hline \multicolumn{12}{|c|}{ Central and South Americans and other Hispanics } \\
\hline Recent immigrants & 9.1 & 0.6 & 0.55 & 0.48 & 0.63 & 14.6 & 0.9 & 0.48 & 0.42 & 0.56 & $60.4 *$ \\
\hline Long-term immigrants & 13.3 & 0.7 & 0.76 & 0.68 & 0.85 & 25.4 & 1.3 & 0.84 & 0.72 & 0.97 & $91.6^{*}$ \\
\hline US-born & 14.8 & 0.7 & 1.15 & 1.02 & 1.29 & 28.0 & 1.4 & 1.29 & 1.12 & 1.49 & $89.6^{*}$ \\
\hline Relative index of disparity & 39.51 & 2.11 & & & & 38.44 & 1.97 & & & & -2.7 \\
\hline \multicolumn{12}{|l|}{ Gender } \\
\hline Male & 14.9 & 0.1 & 1.00 & \multicolumn{2}{|c|}{ Reference } & 25.4 & 0.2 & 1.00 & \multicolumn{2}{|c|}{ Reference } & $70.4^{*}$ \\
\hline Female & 15.1 & 0.1 & 0.96 & 0.94 & 0.99 & 25.2 & 0.2 & 0.96 & 0.93 & 0.99 & $66.9 *$ \\
\hline \multicolumn{12}{|c|}{ Education (years of school completed) } \\
\hline $0-8$ & 20.9 & 0.3 & 1.90 & 1.80 & 2.01 & 28.0 & 0.6 & 1.63 & 1.51 & 1.76 & $34.3^{*}$ \\
\hline $9-11$ & 19.0 & 0.3 & 1.71 & 1.63 & 1.79 & 29.1 & 0.4 & 1.64 & 1.55 & 1.74 & $52.9 *$ \\
\hline 12 & 16.0 & 0.1 & 1.46 & 1.40 & 1.51 & 28.2 & 0.3 & 1.55 & 1.47 & 1.62 & $76.5^{*}$ \\
\hline $13-15$ & 13.6 & 0.2 & 1.34 & 1.29 & 1.39 & 26.7 & 0.3 & 1.54 & 1.47 & 1.61 & $95.7 *$ \\
\hline $16+$ & 10.3 & 0.1 & 1.00 & \multicolumn{2}{|c|}{ Reference } & 18.4 & 0.3 & 1.00 & \multicolumn{2}{|c|}{ Reference } & $78.8^{*}$ \\
\hline Relative index of disparity & 54.95 & 0.22 & & & & 41.62 & 0.01 & & & & $-24.3 *$ \\
\hline $\operatorname{Gamma}(\gamma)$ & -0.19 & 0.004 & & & & -0.14 & 0.004 & & & & $-26.3^{*}$ \\
\hline \multicolumn{12}{|l|}{ Family income (\$) } \\
\hline$<10,000$ & 20.0 & 0.5 & 1.62 & 1.51 & 1.74 & 28.4 & 0.7 & 1.44 & 1.32 & 1.58 & $42.3 *$ \\
\hline $10,000-19,999$ & 18.7 & 0.3 & 1.56 & 1.48 & 1.64 & 27.2 & 0.5 & 1.36 & 1.27 & 1.45 & $45.3 *$ \\
\hline $20,000-24,999$ & 17.4 & 0.3 & 1.45 & 1.38 & 1.53 & 26.1 & 0.6 & 1.26 & 1.16 & 1.36 & $49.7 *$ \\
\hline $25,000-34,999$ & 16.4 & 0.3 & 1.39 & 1.31 & 1.46 & 27.1 & 0.5 & 1.30 & 1.22 & 1.39 & $65.1^{*}$ \\
\hline $35,000-44,999$ & 15.5 & 0.2 & 1.30 & 1.25 & 1.36 & 27.8 & 0.5 & 1.32 & 1.24 & 1.41 & $79.6^{*}$ \\
\hline $45,000-64,999$ & 14.8 & 0.2 & 1.23 & 1.18 & 1.28 & 26.2 & 0.5 & 1.19 & 1.12 & 1.26 & $77.7 *$ \\
\hline $65,000+$ & 11.7 & 0.2 & 1.00 & \multicolumn{2}{|c|}{ Reference } & 22.1 & 0.3 & 1.00 & \multicolumn{2}{|c|}{ Reference } & $88.5^{*}$ \\
\hline Relative index of disparity & 39.34 & 0.39 & & & & 19.40 & 0.52 & & & & $-50.7^{*}$ \\
\hline $\operatorname{Gamma}(\gamma)$ & -0.14 & 0.004 & & & & -0.08 & 0.005 & & & & $-42.9 *$ \\
\hline \multicolumn{12}{|c|}{ Poverty status (ratio of family income to poverty threshold) } \\
\hline$<100 \%$ & & & & & & 28.3 & 0.5 & 1.33 & 1.25 & 1.42 & \\
\hline $100-199 \%$ & & & & & & 28.3 & 0.4 & 1.29 & 1.22 & 1.36 & \\
\hline $200-299 \%$ & & & & & & 27.7 & 0.4 & 1.24 & 1.18 & 1.31 & \\
\hline $300-399 \%$ & & & & & & 27.4 & 0.4 & 1.22 & 1.16 & 1.29 & \\
\hline $400-499 \%$ & & & & & & 24.8 & 0.5 & 1.10 & 1.03 & 1.16 & \\
\hline$\geq 500 \%$ & & & & & & 22.2 & 0.3 & 1.00 & Refer & & \\
\hline Relative index of disparity & & & & & & 19.16 & 0.22 & & & & \\
\hline $\operatorname{Gamma}(\gamma)$ & & & & & & -0.09 & 0.004 & & & & \\
\hline \multicolumn{12}{|l|}{ Occupation } \\
\hline Professional/managerial & 12.5 & 0.2 & 1.00 & Refer & & 22.0 & 0.3 & 1.00 & Refer & & $75.9 *$ \\
\hline Sales/clerical/technical support & 13.7 & 0.2 & 0.97 & 0.93 & 1.01 & 25.5 & 0.3 & 1.02 & 0.98 & 1.07 & $86.2^{*}$ \\
\hline Service & 16.5 & 0.3 & 1.05 & 1.00 & 1.10 & 27.5 & 0.4 & 1.07 & 1.01 & 1.13 & $66.8^{*}$ \\
\hline Craft and repair & 15.4 & 0.3 & 0.94 & 0.89 & 0.99 & 27.6 & 0.4 & 0.98 & 0.93 & 1.04 & $78.8^{*}$ \\
\hline Laborers & 17.7 & 0.2 & 1.06 & 1.01 & 1.11 & 31.5 & 0.5 & 1.21 & 1.14 & 1.29 & $78.4^{*}$ \\
\hline Unemployed/not in labor force & 16.1 & 0.2 & 1.06 & 1.03 & 1.10 & 22.7 & 0.6 & 1.00 & 0.92 & 1.08 & $40.7 *$ \\
\hline Relative index of disparity & 21.14 & 0.21 & & & & 21.85 & 0.09 & & & & $3.4^{*}$ \\
\hline $\operatorname{Gamma}(\gamma)$ & -0.11 & 0.004 & & & & -0.09 & 0.004 & & & & $-18.2 *$ \\
\hline
\end{tabular}


Table 1 continued

All chi-square tests for independence between each covariate (except gender) and obesity prevalence were statistically significant at $P<.05$

* Increases in obesity prevalence or changes in gamma or disparity indices during 1992-2008 were statistically significantly different from 0 $(P<.05)$

a Adjusted by logistic regression for survey year, age, gender, ethnic-immigrant status (or race/ethnicity and length of immigration), marital status, family size, region of residence, education, occupation, and family income or poverty status

${ }^{\mathrm{b}}$ Recent immigrants were those who immigrated to the US $<15$ years previous. Long-term immigrants were those who had been in the US $\geq 15$ years

categorical variable and a continuous variable. The seven income strata for 2003-2006 were: $<10,000$, 10,00019,999, 20,000-24,999, 25,000-34,999, 35,000-44,999, $45,000-64,999$, and $\geq 65,000$. The corresponding income strata for 1992-1995 were: <7,000, 7,000-14,999, 15,00019,999, 20,000-24,999, 25,000-34,999, 35,000-49,999, and $\geq 50,000$. Detailed income categories were not available for 2007-2008. The income categories were roughly comparable for the 1992-1995 and 2003-2006 periods, given an increase by a factor of about 1.3 in the consumer price index between 1995 and 2005 [20]. Continuous income was measured in thousands of dollars for both time periods.

Occupational class was defined in terms of 5 broad categories: professional and managerial occupations, sales/ clerical and technical support occupations, service, craft and repair, and laborers. These occupational groups, derived from the major occupational groups defined by the Census Bureau, are consistent with previously defined social class positions of upper white collar, lower white collar, upper blue collar, and lower blue collar jobs [20, 21]. "Professional and managerial" occupations included executives, managers, administrators, engineers, architects, mathematical and computer scientists, teachers, writers, artists, and other professional specialty occupations. "Sales/clerical and technical support" occupations included technicians, health technologists, sales workers, computer equipment operators, secretaries, typists, and financial records processing, mail, message distributing, and other administrative support occupations. "Service" occupations included private household, protective service, food service, health service, cleaning and building service occupations, farm and other agricultural workers. "Craft and repair" occupations included mechanics, repairers, and those in construction, extractive trades, and precision production jobs. "Laborers" included machine operators, fabricators, assemblers, motor vehicle and material moving equipment operators, construction laborers, handlers, equipment cleaners, and helpers. In addition, a residual category for the unemployed and those outside the labor force was used.

PA level was measured by the number of times/week of vigorous activities of at least $10 \mathrm{~min}$ that caused heavy sweating or large increases in breathing or heart rate. The variable was coded as $<1,1-2,3-4, \geq 5$ times/week of activity. PA was not available in 1976 and 1992-1995 [18].

Multivariate logistic regression was used to examine the association between the binary outcomes of obesity and overweight and selected socioeconomic and demographic factors. Least squares regression was used to model mean BMI. To account for the complex sample design of the NHIS, SUDAAN software was used to conduct all statistical analyses [22].

The two-sample $t$ test was used to test the difference in prevalence between any two groups at one point in time or to test for change in prevalence between two time points for a specific group. The gamma $(\gamma)$ statistic, varying between -1 and 1 , was used to measure the magnitude of the association between an ordinal covariate and obesity [16]. An index of disparity (ID), which approximated in relative terms the average deviation of the rates from the rate for the best-off ethnic-immigrant or socioeconomic group, was used to summarize disparities across all social groups [16, 23]. The relative mean deviation index of disparity was calculated as:

$\mathrm{ID}=\left\{\left(\sum_{i}\left|O_{\mathrm{ri}}-O_{\mathrm{rl}}\right| / I\right) / O_{\mathrm{rl}}\right\} \times 100 ; \quad O_{\mathrm{rl}}>0$

where $O_{\text {ri }}$ is the obesity/overweight prevalence for the ith group, $O_{\mathrm{rl}}$ is the rate for the "standard" group or group with the lowest obesity/overweight prevalence, and I is the number of groups. A simulation method was used to estimate the standard error for ID [24].

\section{Results}

Annual Trends in Obesity and Overweight Prevalence by Immigrant Status and Educational Attainment, 1976 and 1991-2008

The obesity prevalence for the total US adult population aged $\geq 18$ tripled from $8.7 \%$ in 1976 to $27.4 \%$ in 2008 . The overweight prevalence for all US adults increased from $36.9 \%$ in 1976 to $62.0 \%$ in 2008 . In 2008, 59 million US adults were obese and 134 million overweight. This represented an absolute increase of 47 million obese and 80 million overweight adults since 1976. 
Table 2 Observed (weighted) prevalence and adjusted odds of overweight (BMI $\geq 25$ ) among 30 ethnic-immigrant groups aged $18+$ years and by selected socioeconomic and demographic characteristics: The National Health Interview Survey, 1992-2008

\begin{tabular}{|c|c|c|c|c|c|c|c|c|c|c|c|}
\hline \multirow[t]{3}{*}{ Covariates } & \multicolumn{5}{|c|}{$1992-1995(N=323,627)$} & \multicolumn{5}{|c|}{ 2003-2008 $(N=154,649)$} & \multirow{3}{*}{$\begin{array}{l}\text { 1992-2008 } \\
\% \text { Increase } \\
\text { in prevalence }\end{array}$} \\
\hline & \multicolumn{2}{|c|}{ Prevalence } & \multicolumn{3}{|c|}{ Adjusted odds ratio $^{a}$} & \multicolumn{2}{|c|}{ Prevalence } & \multicolumn{3}{|c|}{ Adjusted odds ratio ${ }^{a}$} & \\
\hline & $\%$ & SE & OR & $95 \%$ & & $\%$ & SE & OR & $95 \%$ & & \\
\hline \multicolumn{12}{|c|}{ Duration of residence in the US (years) } \\
\hline$<1$ & 25.9 & 1.7 & 0.51 & 0.43 & 0.60 & 37.7 & 3.3 & 0.43 & 0.32 & 0.58 & $45.5^{*}$ \\
\hline $1-5$ & 32.8 & 0.9 & 0.66 & 0.60 & 0.71 & 45.4 & 1.3 & 0.58 & 0.52 & 0.65 & $38.3 *$ \\
\hline $5-9$ & 38.7 & 0.6 & 0.71 & 0.67 & 0.76 & 49.9 & 1.0 & 0.58 & 0.53 & 0.64 & $29.0^{*}$ \\
\hline $10-14$ & 41.2 & 0.9 & 0.79 & 0.74 & 0.86 & 55.2 & 1.0 & 0.71 & 0.64 & 0.78 & $33.9 *$ \\
\hline $15+$ & 48.1 & 0.5 & 0.89 & 0.85 & 0.92 & 60.9 & 0.5 & 0.82 & 0.78 & 0.87 & $26.7^{*}$ \\
\hline US-born & 48.3 & 0.2 & 1.00 & \multicolumn{2}{|c|}{ Reference } & 61.3 & 0.2 & 1.00 & \multicolumn{2}{|c|}{ Reference } & $26.9 *$ \\
\hline Relative index of disparity & 18.89 & 1.37 & & & & 15.60 & 1.73 & & & & -17.4 \\
\hline $\operatorname{Gamma}(\gamma)$ & 0.09 & 0.005 & & & & 0.09 & 0.006 & & & & 0.0 \\
\hline \multicolumn{12}{|l|}{ Non-Hispanic White } \\
\hline Recent immigrants $^{\mathrm{b}}$ & 39.0 & 1.3 & 0.81 & 0.73 & 0.91 & 46.3 & 1.7 & 0.70 & 0.61 & 0.81 & $18.5 *$ \\
\hline Long-term immigrants ${ }^{\mathrm{b}}$ & 46.2 & 0.7 & 0.92 & 0.86 & 0.97 & 58.0 & 1.1 & 0.91 & 0.83 & 0.99 & $25.5^{*}$ \\
\hline US-born & 46.7 & 0.2 & 1.00 & \multicolumn{2}{|c|}{ Reference } & 59.6 & 0.2 & 1.00 & \multicolumn{2}{|c|}{ Reference } & $27.8^{*}$ \\
\hline \multicolumn{12}{|l|}{ Non-Hispanic Black } \\
\hline Recent immigrants & 49.4 & 1.7 & 1.32 & 1.17 & 1.49 & 51.4 & 1.9 & 0.83 & 0.71 & 0.97 & 4.1 \\
\hline Long-term immigrants & 55.8 & 1.4 & 1.40 & 1.23 & 1.59 & 67.7 & 1.9 & 1.35 & 1.12 & 1.62 & $21.4^{*}$ \\
\hline US-born & 58.4 & 0.3 & 1.79 & 1.74 & 1.84 & 69.7 & 0.4 & 1.72 & 1.65 & 1.79 & $19.3 *$ \\
\hline American Indian/Alaska Native & 56.3 & 1.4 & 1.59 & 1.40 & 1.80 & 69.6 & 2.0 & 1.58 & 1.31 & 1.92 & $23.5^{*}$ \\
\hline \multicolumn{12}{|l|}{ Chinese } \\
\hline Recent immigrants & 15.0 & 1.0 & 0.22 & 0.19 & 0.26 & 19.8 & 2.3 & 0.19 & 0.14 & 0.26 & 32.2 \\
\hline Long-term immigrants & 21.3 & 2.2 & 0.28 & 0.22 & 0.37 & 23.2 & 2.2 & 0.19 & 0.15 & 0.24 & 9.1 \\
\hline US-born & 24.6 & 2.3 & 0.50 & 0.41 & 0.60 & 40.1 & 3.3 & 0.64 & 0.48 & 0.85 & $63.3 *$ \\
\hline \multicolumn{12}{|l|}{ Filipino } \\
\hline Recent immigrants & 23.8 & 1.6 & 0.42 & 0.35 & 0.51 & 39.6 & 3.4 & 0.51 & 0.39 & 0.67 & $66.8^{*}$ \\
\hline Long-term immigrants & 32.6 & 2.4 & 0.56 & 0.45 & 0.71 & 47.7 & 2.4 & 0.59 & 0.48 & 0.73 & $46.3 *$ \\
\hline US-born & 35.7 & 5.4 & 0.91 & 0.6 & 1.38 & 54.5 & 3.5 & 1.03 & 0.77 & 1.36 & $52.6^{*}$ \\
\hline \multicolumn{12}{|l|}{ Asian Indian } \\
\hline Recent immigrants & 26.4 & 1.9 & 0.46 & 0.38 & 0.57 & 37.7 & 2.2 & 0.51 & 0.42 & 0.62 & $42.5^{*}$ \\
\hline Long-term immigrant/US-born & 36.6 & 2.5 & 0.66 & 0.54 & 0.81 & 46.0 & 2.9 & 0.59 & 0.47 & 0.74 & $25.5^{*}$ \\
\hline \multicolumn{12}{|l|}{ Other Asian and Pacific Islanders } \\
\hline Recent immigrants & 18.9 & 1.1 & 0.29 & 0.25 & 0.34 & 23.0 & 1.8 & 0.23 & 0.18 & 0.29 & 21.8 \\
\hline Long-term immigrants & 23.5 & 1.4 & 0.36 & 0.31 & 0.42 & 34.4 & 1.6 & 0.33 & 0.29 & 0.38 & $46.2 *$ \\
\hline US-born & 35.9 & 1.2 & 0.79 & 0.70 & 0.88 & 49.2 & 3.0 & 0.81 & 0.65 & 1.03 & $37.1 *$ \\
\hline Mexican & & & & & & & & & & & \\
\hline Recent immigrants & 49.0 & 0.9 & 1.21 & 1.12 & 1.31 & 60.7 & 0.9 & 1.19 & 1.08 & 1.30 & $23.8 *$ \\
\hline Long-term immigrants & 62.2 & 0.8 & 1.63 & 1.52 & 1.74 & 73.9 & 0.8 & 1.60 & 1.45 & 1.76 & $18.7^{*}$ \\
\hline US-born & 56.9 & 0.7 & 1.79 & 1.69 & 1.90 & 69.3 & 0.7 & 1.81 & 1.68 & 1.95 & $21.9^{*}$ \\
\hline Puerto Rican & & & & & & & & & & & \\
\hline Recent immigrants & 50.6 & 2.1 & 1.36 & 1.13 & 1.63 & 59.3 & 3.4 & 1.19 & 0.90 & 1.56 & $17.2^{*}$ \\
\hline Long-term immigrants & 61.4 & 1.2 & 1.51 & 1.36 & 1.68 & 71.2 & 1.9 & 1.51 & 1.26 & 1.82 & $16.0^{*}$ \\
\hline US-born & 46.9 & 1.4 & 1.30 & 1.16 & 1.47 & 65.9 & 1.7 & 1.50 & 1.29 & 1.75 & $40.7 *$ \\
\hline Cuban & & & & & & & & & & & \\
\hline Recent immigrants & 55.3 & 2.1 & 1.28 & 1.09 & 1.51 & 64.7 & 3.7 & 1.12 & 0.79 & 1.60 & $17.1^{*}$ \\
\hline Long-term immigrants & 55.3 & 2.4 & 1.25 & 1.03 & 1.51 & 64.8 & 2.4 & 1.04 & 0.86 & 1.27 & $17.1 *$ \\
\hline US-born & 46.0 & 2.2 & 1.23 & 1.02 & 1.48 & 56.5 & 3.4 & 1.12 & 0.84 & 1.48 & $23.0 *$ \\
\hline
\end{tabular}


Table 2 continued

\begin{tabular}{|c|c|c|c|c|c|c|c|c|c|c|c|}
\hline \multirow[t]{3}{*}{ Covariates } & \multicolumn{5}{|c|}{$1992-1995(N=323,627)$} & \multicolumn{5}{|c|}{ 2003-2008 $(N=154,649)$} & \multirow{3}{*}{$\begin{array}{l}\text { 1992-2008 } \\
\% \text { Increase } \\
\text { in prevalence }\end{array}$} \\
\hline & \multicolumn{2}{|c|}{ Prevalence } & \multicolumn{3}{|c|}{ Adjusted odds ratio ${ }^{a}$} & \multicolumn{2}{|c|}{ Prevalence } & \multicolumn{3}{|c|}{ Adjusted odds ratio ${ }^{a}$} & \\
\hline & $\%$ & SE & OR & $95 \%$ & & $\%$ & SE & OR & $95 \%$ & & \\
\hline \multicolumn{12}{|c|}{ Central and South Americans and other Hispanics } \\
\hline Recent immigrants & 40.7 & 1.3 & 0.86 & 0.77 & 0.95 & 54.4 & 1.4 & 0.86 & 0.76 & 0.97 & $33.7 *$ \\
\hline Long-term immigrants & 49.4 & 1.1 & 1.02 & 0.92 & 1.12 & 69.1 & 1.2 & 1.32 & 1.17 & 1.49 & $39.9 *$ \\
\hline US-born & 47.8 & 1.1 & 1.26 & 1.16 & 1.37 & 64.4 & 1.4 & 1.50 & 1.32 & 1.69 & $34.8^{*}$ \\
\hline Relative index of disparity & 23.92 & 0.78 & & & & 20.56 & 1.26 & & & & $-14.0^{*}$ \\
\hline \multicolumn{12}{|l|}{ Gender } \\
\hline Male & 57.0 & 0.2 & 1.00 & \multicolumn{2}{|c|}{ Reference } & 68.1 & 0.2 & 1.00 & \multicolumn{2}{|c|}{ Reference } & $19.6^{*}$ \\
\hline Female & 39.1 & 0.2 & 0.45 & 0.44 & 0.46 & 53.1 & 0.3 & 0.50 & 0.48 & 0.51 & $35.8^{*}$ \\
\hline \multicolumn{12}{|c|}{ Education (years of school completed) } \\
\hline $0-8$ & 56.7 & 0.3 & 1.50 & 1.44 & 1.56 & 66.0 & 0.6 & 1.39 & 1.29 & 1.49 & $16.5^{*}$ \\
\hline $9-11$ & 52.1 & 0.3 & 1.44 & 1.38 & 1.49 & 62.2 & 0.5 & 1.38 & 1.30 & 1.45 & $19.5^{*}$ \\
\hline 12 & 49.1 & 0.2 & 1.31 & 1.28 & 1.35 & 63.5 & 0.3 & 1.40 & 1.35 & 1.46 & $29.5^{*}$ \\
\hline $13-15$ & 44.8 & 0.2 & 1.23 & 1.20 & 1.27 & 61.1 & 0.3 & 1.42 & 1.36 & 1.47 & $36.4^{*}$ \\
\hline $16+$ & 42.3 & 0.3 & 1.00 & \multicolumn{2}{|c|}{ Reference } & 54.5 & 0.3 & 1.00 & \multicolumn{2}{|c|}{ Reference } & $28.9^{*}$ \\
\hline Relative index of disparity & 15.86 & 0.08 & & & & 12.84 & 0.07 & & & & $-19.0^{*}$ \\
\hline $\operatorname{Gamma}(\gamma)$ & -0.13 & 0.003 & & & & -0.12 & 0.004 & & & & -7.7 \\
\hline \multicolumn{12}{|l|}{ Family income (\$) } \\
\hline$<10,000$ & 48.4 & 0.8 & 1.24 & 1.16 & 1.33 & 57.7 & 0.8 & 1.10 & 1.02 & 1.19 & $19.2 *$ \\
\hline $10,000-19,999$ & 49.7 & 0.4 & 1.23 & 1.18 & 1.28 & 59.8 & 0.5 & 1.12 & 1.05 & 1.19 & $20.4 *$ \\
\hline $20,000-24,999$ & 50.4 & 0.4 & 1.22 & 1.18 & 1.27 & 61.2 & 0.7 & 1.14 & 1.05 & 1.22 & $21.6^{*}$ \\
\hline $25,000-34,999$ & 49.3 & 0.4 & 1.18 & 1.14 & 1.22 & 61.4 & 0.6 & 1.11 & 1.05 & 1.18 & $24.5^{*}$ \\
\hline $35,000-44,999$ & 49.5 & 0.3 & 1.19 & 1.16 & 1.23 & 62.7 & 0.6 & 1.14 & 1.07 & 1.21 & $26.7^{*}$ \\
\hline $45,000-64,999$ & 48.9 & 0.3 & 1.15 & 1.12 & 1.18 & 62.4 & 0.5 & 1.11 & 1.05 & 1.17 & $27.6^{*}$ \\
\hline $65,000+$ & 45.0 & 0.2 & 1.00 & \multicolumn{2}{|c|}{ Reference } & 59.2 & 0.4 & 1.00 & \multicolumn{2}{|c|}{ Reference } & $31.6^{*}$ \\
\hline Relative index of disparity & 8.39 & 0.27 & & & & 3.16 & 0.11 & & & & $-62.3^{*}$ \\
\hline $\operatorname{Gamma}(\gamma)$ & -0.06 & 0.003 & & & & -0.01 & 0.005 & & & & $-83.3^{*}$ \\
\hline \multicolumn{12}{|c|}{ Poverty status (ratio of family income to poverty threshold) } \\
\hline$<100 \%$ & & & & & 58.6 & 0.6 & 1.12 & 1.06 & 1.18 & & \\
\hline $100-199 \%$ & & & & & 62.0 & 0.4 & 1.15 & 1.09 & 1.2 & & \\
\hline $200-299 \%$ & & & & & 62.3 & 0.4 & 1.12 & 1.07 & 1.17 & & \\
\hline $300-399 \%$ & & & & & 62.4 & 0.5 & 1.12 & 1.07 & 1.18 & & \\
\hline $400-499 \%$ & & & & & 62.2 & 0.5 & 1.12 & 1.06 & 1.19 & & \\
\hline$\geq 500 \%$ & & & & & 59.4 & 0.4 & 1.00 & Refe & & & \\
\hline Relative index of disparity & & & & & 3.39 & 0.02 & & & & & \\
\hline $\operatorname{Gamma}(\gamma)$ & & & & & -0.01 & 0.004 & & & & & \\
\hline \multicolumn{12}{|l|}{ Occupation } \\
\hline Professional/managerial & 45.4 & 0.2 & 1.00 & Refer & & 58.1 & 0.3 & 1.00 & Refer & & $28.2 *$ \\
\hline Sales/clerical/technical support & 43.1 & 0.2 & 0.98 & 0.95 & 1.00 & 58.3 & 0.3 & 1.04 & 1.00 & 1.08 & $35.4^{*}$ \\
\hline Service & 48.6 & 0.4 & 1.07 & 1.03 & 1.10 & 61.1 & 0.4 & 1.07 & 1.02 & 1.12 & $25.7 *$ \\
\hline Craft and repair & 58.1 & 0.4 & 1.05 & 1.02 & 1.09 & 68.5 & 0.4 & 0.99 & 0.94 & 1.04 & $17.8^{*}$ \\
\hline Laborers & 55.8 & 0.3 & 1.09 & 1.05 & 1.13 & 69.5 & 0.5 & 1.13 & 1.07 & 1.20 & $24.6^{*}$ \\
\hline Unemployed/not in labor force & 47.1 & 0.2 & 0.99 & 0.96 & 1.01 & 50.4 & 0.7 & 0.91 & 0.85 & 0.97 & $7.1^{*}$ \\
\hline Relative index of disparity & 12.87 & 0.10 & & & & 8.43 & 0.06 & & & & $-34.5^{*}$ \\
\hline $\operatorname{Gamma}(\gamma)$ & -0.13 & 0.003 & & & & -0.13 & 0.004 & & & & 0.00 \\
\hline
\end{tabular}


Table 2 continued

All Chi-square tests for independence between each covariate and overweight prevalence were statistically significant at $P<.05$

* Increases in overweight prevalence or changes in gamma/disparity indices during 1992-2008 were statistically significantly different from 0 $(P<.05)$

a Adjusted by logistic regression for survey year, age, gender, ethnic-immigrant status (or race/ethnicity and length of immigration), marital status, family size, region of residence, education, occupation, and family income or poverty status

${ }^{\mathrm{b}}$ Recent immigrants were those who immigrated to the US $<15$ years previous. Long-term immigrants were those who had been in the US $\geq 15$ years

During 1991-2008, the obesity prevalence for US-born adults increased from 13.9 to $28.7 \%$, whereas the prevalence for immigrants increased from 9.5 to $20.7 \%$ (Fig. 1). The average annual rates of increase for the two groups were $4.5 \%$ and $4.6 \%$, respectively. During 1991-2008, increases in overweight prevalence were equally marked among both US-born and immigrant adults, with the prevalence for the US-born rising from 45.7 to $62.7 \%$, while that for immigrants rising from 39.6 to $58.4 \%$. Immigrant differentials in BMI increased over time. The mean BMI for the US-born increased from 25.24 in 1991 to 27.75 in 2008, while for immigrants it increased from 24.55 to 26.56 (Fig. 1).

Annual trends by educational attainment show persistent disparities in obesity and overweight prevalence and BMI (Fig. 1). Educational gradients were more consistent and pronounced in 1976 and the 1990s than during the first decade of the 2000s. The rate of increase in obesity and overweight was greater for those with 12, 13-15 and $\geq 16$ years of education than for those with $0-8$ and 9-11 years of education. During 1991-2008, the average annual rates of increase in obesity for the 5 (low to high) educational groups were $2.58,3.63,4.75,5.54$, and $5.05 \%$, respectively. The corresponding rates of increase in overweight were $1.36,1.90,2.32,2.90$, and $2.25 \%$.

Socioeconomic Profiles of Ethnic-Immigrant Groups, 2003-2008

The immigrant groups varied substantially in their socioeconomic characteristics (Fig. 2). Overall, immigrants had nearly twice the poverty levels of the US-born. They were also twice as likely to be without a high school diploma as the US-born. Socioeconomic achievement levels increased with increasing duration of residence in the US. During 2003-2008, less than 6\% of Mexican immigrants were college graduates, compared with $67 \%$ of recent Asian Indian immigrants. Less than $9 \%$ of Mexican immigrants were employed in professional and managerial occupations, as compared with $52 \%$ of recent Asian Indian immigrants and $53 \%$ of US-born Chinese. Poverty rates varied from a low of 5\% for long-term Filipino immigrants to a high of $33 \%$ for recent Mexican immigrants.
Ethnic-immigrant and Socioeconomic Disparities in Obesity and Overweight Prevalence, 1976, 1992-1995, and 2003-2008

Table 1 shows increases in obesity prevalence between 1992-1995 and 2003-2008 for detailed ethnic-immigrant and socioeconomic groups. Regardless of ethnicity, all immigrant groups experienced a substantial increase in prevalence, with the increase being greater among the US-born population and longer-term immigrants.

Tables 1 and 2 show considerable disparities in obesity and overweight prevalence by immigrant status and selected socioeconomic factors. The observed obesity prevalence in 2003-2008 ranged from 2.3\% for recent Chinese immigrants to $30.6 \%$ or higher for American Indians, US-born blacks, Mexicans, and Puerto Ricans, and long-term Mexican and Puerto Rican immigrants (Table 1). The overweight prevalence in 2003-2008 ranged from $19.8 \%$ for recent Chinese immigrants to $70 \%$ or higher for American Indians, US-born blacks and Mexicans, and long-term Mexican and Puerto Rican immigrants (Table 2). Mean BMI in 2003-2008 varied from a low of 22.6 for recent Chinese immigrants to a high for 28.9 for US-born blacks and American Indians, and 28.6 for USborn Mexicans (Table 3). The summary index of disparity showed similar ethnic-immigrant disparities in obesity and overweight prevalence in 1992-1995 and 2003-2008.

The odds and prevalence of obesity and overweight, even after adjusting for sociodemographic factors, increased with increasing duration in the US (Tables 1,2). The obesity gradients by length of immigration were steeper in 2003-2008 than in 1992-1995. Compared with the US-born, immigrants who had lived in the US for $<1$ year or $\geq 15$ years had 73 or $34 \%$ lower odds of obesity in 2003-2008 and 59 or $28 \%$ lower odds of obesity in 1992-1995, respectively (Table 1). Immigrants who had lived in the US for $<1$ year or $\geq 15$ years had 57 or $18 \%$ lower odds of overweight than the US-born in 2003-2008 (Table 2). During 1992-2008, the disparity indices suggest a slight increase in obesity differentials between US-born and immigrants of various durations.

Compared with US-born whites, the odds of obesity were 59 and $25 \%$ lower for recent and long-term white 


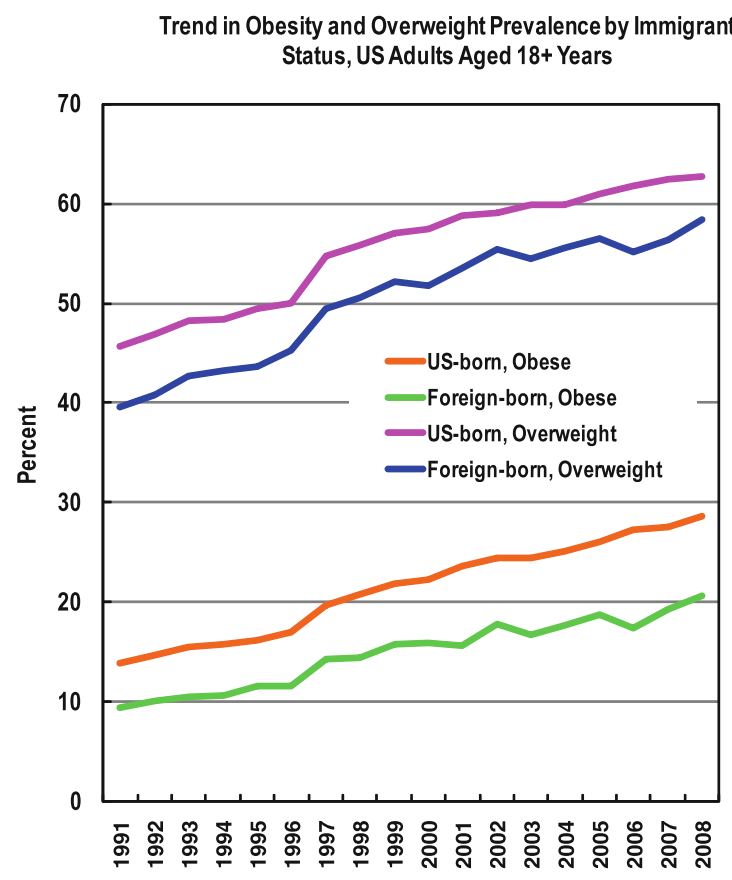

Trend in Body Mass Index by Immigrant Status, US Adults Aged 18+ Years

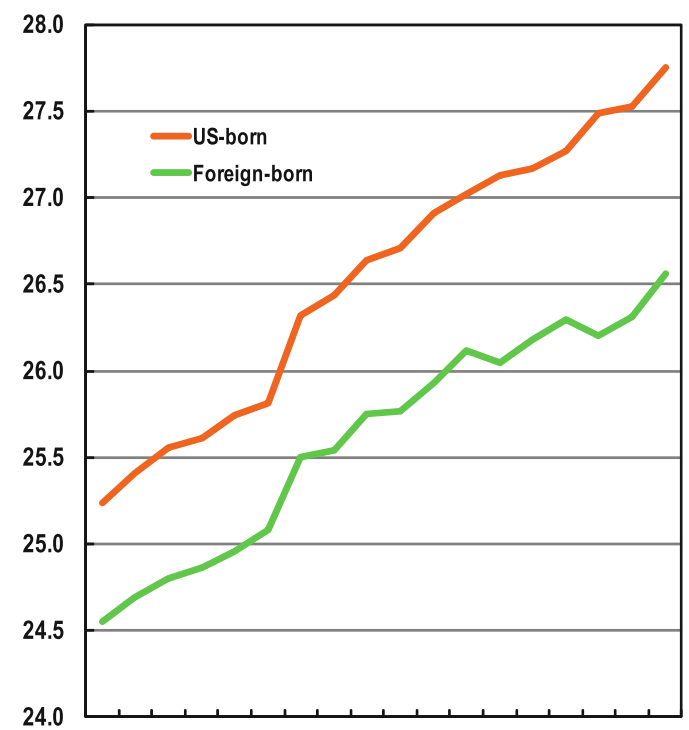

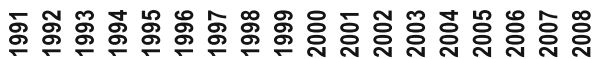

Trend in Obesity and Overweight Prevalence by

Educational Attainment, US Adults Aged 25+ Years

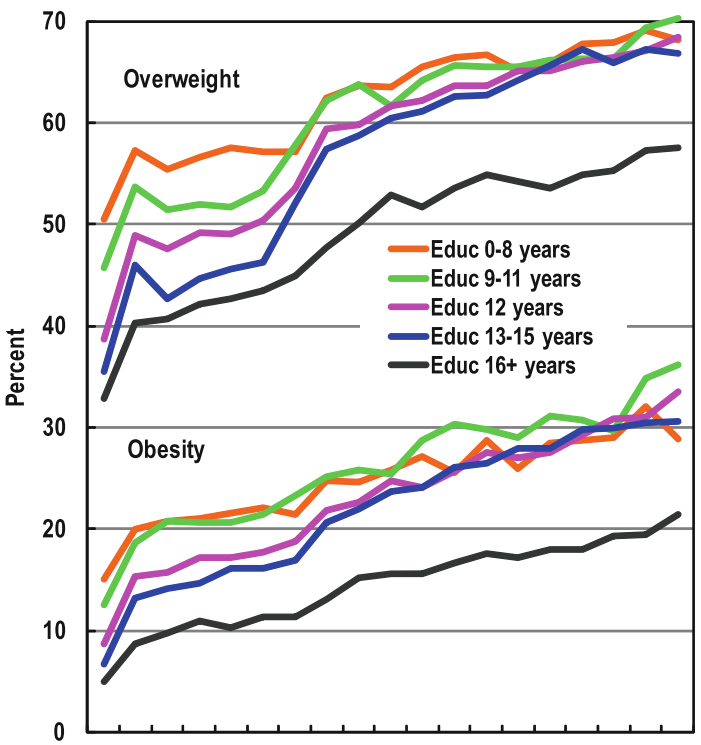

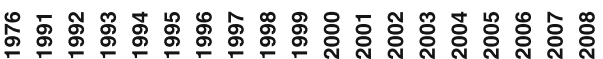

Trend in Body Mass Index by Educational Attainment US Adults Aged 25+Years

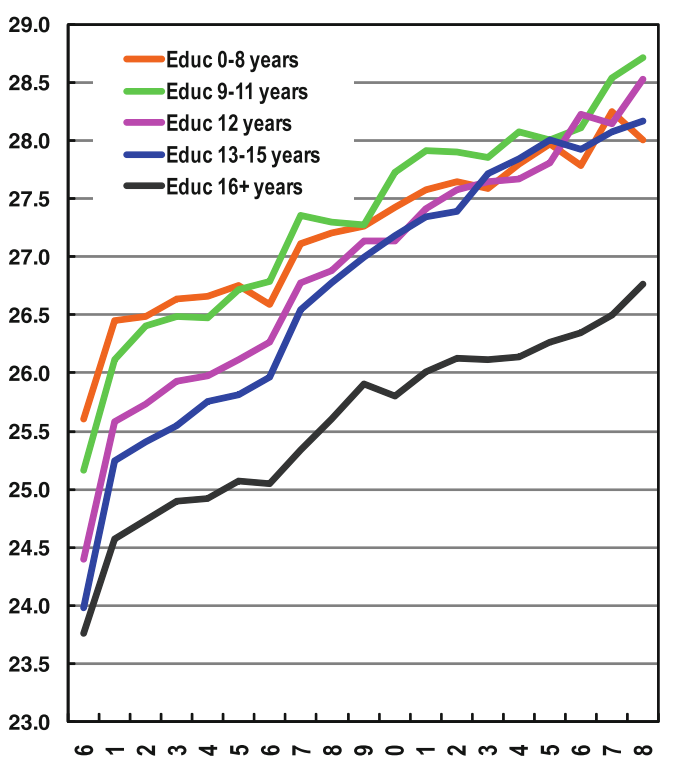

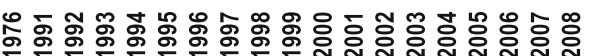

Fig. 1 Trends in Obesity and Overweight Prevalence (\%) among US Adults by Immigrant Status and Education, 1976-2008

immigrants, 36\% lower for recent black immigrants, 5592\% lower for US- and foreign-born Chinese, Asian Indians, and Filipino immigrants, 34-52\% lower for recent Mexican and Central/South American immigrants, respectively. However, US-born blacks, American Indians, Mexicans, and Puerto Ricans, and long-term Puerto Rican immigrants had 60,81, 64, 32, and $23 \%$ higher odds of obesity, respectively than US-born whites (Table 1).
Compared with Chinese immigrants, US-born blacks, Mexicans, Puerto Ricans, and Central/South Americans, and American Indians had 14-19 times higher odds of obesity, whereas white, black, Mexican, Cuban, and Central/South American immigrants had 4-13 times higher odds of obesity. Compared with Chinese immigrants, all other ethnic-immigrant groups had 3-10 times higher odds of overweight (Table 4). 
Fig. 2 Selected Socioeconomic Characteristics (\%) of 30 Ethnic-Immigrant Groups, US Adults Aged 18 years and Older, 2003-2008

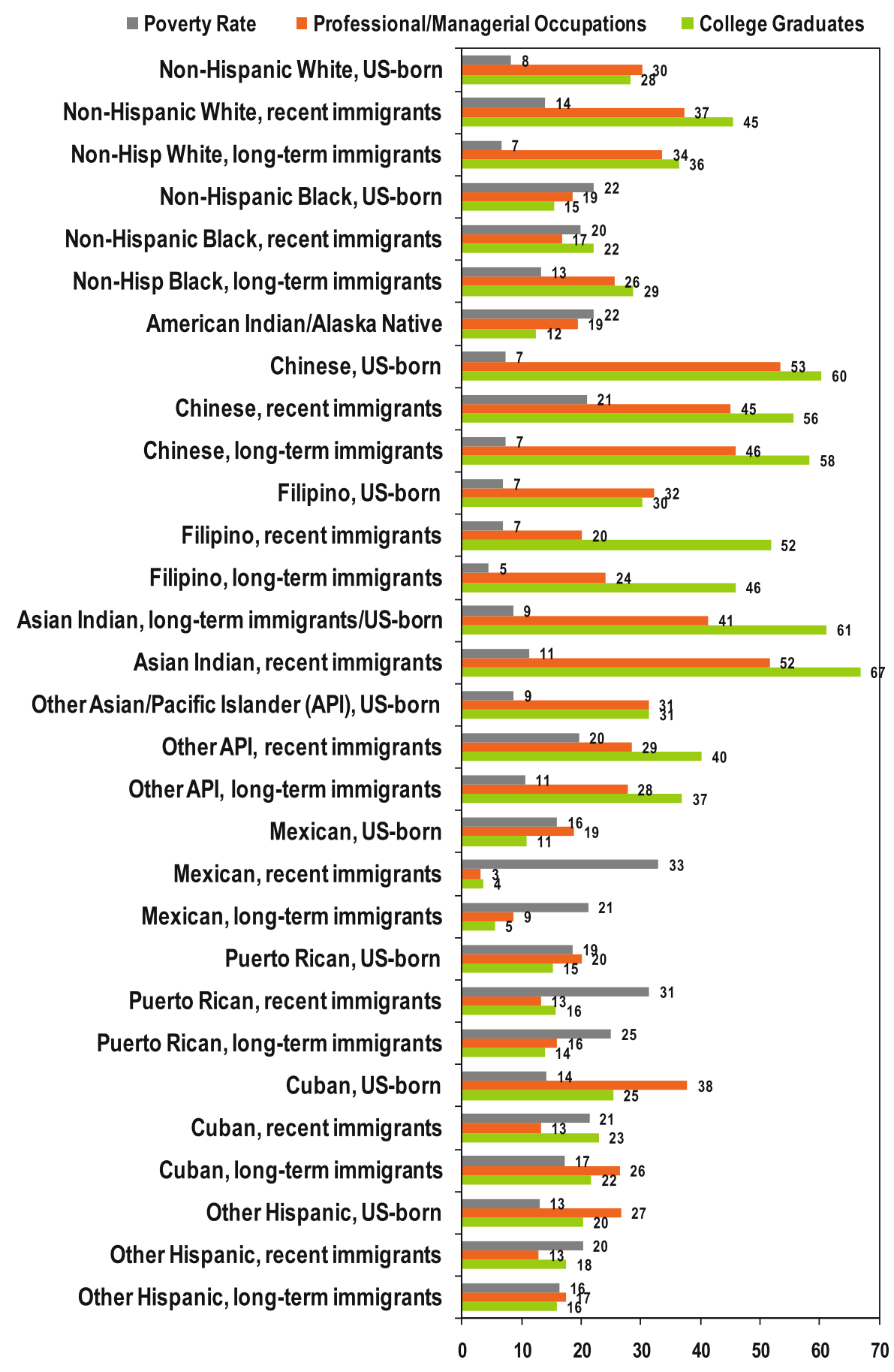

Socioeconomic gradients in obesity, although substantial in each period, were less pronounced in 2003-2008 than in 1992-1995 and 1976. The summary indices also indicate decreasing educational disparities over time. Between 1976 and 2008, obesity prevalence doubled for those with $<9$ years of education, while it increased 4-5 fold for those with a college education. Those with $<9$ years of education had $152 \%$ higher adjusted odds of obesity in 1976, 90\% higher odds in 1992-1995, and $63 \%$ higher odds in 2003-2008 than those with a college degree. In terms of continuous education, each additional year of education was associated with $11 \%$ lower odds of obesity $(\mathrm{OR}=0.89 ; 95 \% \mathrm{CI}=0.89-0.90)$ and $7 \%$ lower odds of overweight $(\mathrm{OR}=0.93 ; 95 \% \mathrm{CI}=0.93-0.94)$ in 1976, 8\% lower odds of obesity (OR $=0.92 ; 95 \%$ $\mathrm{CI}=0.92-0.92)$ and $6 \%$ lower odds of overweight $(\mathrm{OR}=0.94 ; 95 \% \mathrm{CI}=0.94-0.94)$ in 1992-1995, and 6\% lower odds of obesity and overweight (OR $=0.94 ; 95 \%$ $\mathrm{CI}=0.94-0.95)$ in 2003-2008. Each additional year of education was associated with a 0.17 point decrease in BMI 
Table 3 Observed and adjusted mean body mass index (BMI) among 30 ethnic-immigrant groups aged 18+ years and by selected sociodemographic characteristics: The National Health Interview Survey, 1992-2008

\begin{tabular}{|c|c|c|c|c|c|c|c|c|c|c|}
\hline \multirow[t]{3}{*}{ Covariates } & \multicolumn{4}{|c|}{$1992-1995(N=323,627)$} & \multicolumn{4}{|c|}{$2003-2008(N=154,649)$} & \multirow{2}{*}{\multicolumn{2}{|c|}{$\frac{1992-2008}{{\text { Increase in } \mathrm{BMI}^{\mathrm{b}}}}$}} \\
\hline & \multicolumn{2}{|c|}{ Observed } & \multicolumn{2}{|c|}{ Adjusted $^{\mathrm{a}}$} & \multicolumn{2}{|c|}{ Observed } & \multicolumn{2}{|c|}{ Adjusted $^{\mathrm{a}}$} & & \\
\hline & BMI & SE & BMI & SE & BMI & SE & BMI & SE & $\%$ & Absolute \\
\hline \multicolumn{11}{|c|}{ Duration of residence in the US (years) } \\
\hline$<1$ & 23.3 & 0.17 & 24.1 & 0.14 & 24.3 & 0.29 & 24.8 & 0.28 & 4.3 & 1.0 \\
\hline $1-5$ & 23.9 & 0.10 & 24.5 & 0.09 & 24.9 & 0.11 & 25.3 & 0.11 & 4.1 & 1.0 \\
\hline $5-9$ & 24.4 & 0.05 & 24.5 & 0.06 & 25.6 & 0.09 & 25.5 & 0.09 & 5.1 & 1.3 \\
\hline $10-14$ & 24.7 & 0.09 & 24.8 & 0.07 & 26.1 & 0.10 & 25.8 & 0.11 & 5.9 & 1.5 \\
\hline $15+$ & 25.4 & 0.05 & 25.1 & 0.04 & 26.8 & 0.05 & 26.4 & 0.06 & 5.8 & 1.5 \\
\hline US-born & 25.6 & 0.02 & 25.6 & 0.02 & 27.4 & 0.03 & 27.4 & 0.03 & 7.1 & 1.8 \\
\hline \multicolumn{11}{|l|}{ Non-Hispanic White } \\
\hline Recent immigrants & 24.5 & 0.11 & 24.8 & 0.10 & 25.0 & 0.15 & 25.5 & 0.15 & 2.0 & 0.5 \\
\hline Long-term immigrants & 25.2 & 0.07 & 25.0 & 0.07 & 26.4 & 0.11 & 26.5 & 0.11 & 5.1 & 1.3 \\
\hline US-born & 25.4 & 0.02 & 25.3 & 0.02 & 27.1 & 0.03 & 27.1 & 0.03 & 6.9 & 1.8 \\
\hline \multicolumn{11}{|l|}{ Non-Hispanic Black } \\
\hline Recent immigrants & 25.4 & 0.14 & 25.6 & 0.13 & 25.9 & 0.22 & 26.1 & 0.22 & 2.3 & 0.6 \\
\hline Long-term immigrants & 26.0 & 0.13 & 25.7 & 0.13 & 27.7 & 0.24 & 27.3 & 0.23 & 6.5 & 1.7 \\
\hline US-born & 27.0 & 0.04 & 27.0 & 0.04 & 28.9 & 0.06 & 28.8 & 0.06 & 7.1 & 1.9 \\
\hline American Indian/AN & 26.6 & 0.18 & 26.6 & 0.19 & 28.9 & 0.32 & 28.7 & 0.31 & 8.6 & 2.3 \\
\hline \multicolumn{11}{|l|}{ Chinese } \\
\hline Recent immigrants & 22.0 & 0.11 & 22.3 & 0.10 & 22.6 & 0.20 & 23.1 & 0.20 & 2.7 & 0.6 \\
\hline Long-term immigrants & 22.8 & 0.16 & 22.7 & 0.16 & 23.1 & 0.16 & 23.2 & 0.16 & 1.5 & 0.4 \\
\hline US-born & 23.2 & 0.29 & 24.1 & 0.22 & 24.3 & 0.29 & 25.5 & 0.30 & 4.7 & 1.1 \\
\hline \multicolumn{11}{|l|}{ Filipino } \\
\hline Recent immigrants & 23.1 & 0.13 & 23.6 & 0.13 & 24.3 & 0.25 & 24.8 & 0.22 & 5.3 & 1.2 \\
\hline Long-term immigrants & 23.8 & 0.16 & 23.9 & 0.16 & 25.5 & 0.20 & 25.5 & 0.20 & 6.8 & 1.6 \\
\hline US-born & 24.6 & 0.46 & 25.5 & 0.38 & 26.4 & 0.40 & 26.9 & 0.37 & 7.4 & 1.8 \\
\hline \multicolumn{11}{|l|}{ Asian Indian } \\
\hline Recent immigrants & 23.2 & 0.16 & 23.6 & 0.16 & 24.0 & 0.16 & 24.8 & 0.16 & 3.6 & 0.8 \\
\hline Long-term imm/US-born & 24.0 & 0.16 & 24.1 & 0.15 & 24.8 & 0.21 & 25.1 & 0.20 & 3.3 & 0.8 \\
\hline \multicolumn{11}{|l|}{ Other Asian/Pacific Islander } \\
\hline Recent immigrants & 22.3 & 0.11 & 22.5 & 0.11 & 22.9 & 0.19 & 23.3 & 0.20 & 2.9 & 0.6 \\
\hline Long-term immigrants & 23.0 & 0.19 & 23.2 & 0.20 & 24.2 & 0.21 & 24.1 & 0.19 & 4.9 & 1.1 \\
\hline US-born & 24.2 & 0.17 & 24.7 & 0.15 & 25.9 & 0.35 & 26.6 & 0.32 & 7.2 & 1.7 \\
\hline \multicolumn{11}{|l|}{ Mexican } \\
\hline Recent immigrants & 25.6 & 0.09 & 25.6 & 0.09 & 26.6 & 0.09 & 26.7 & 0.10 & 4.1 & 1.1 \\
\hline Long-term immigrants & 26.9 & 0.11 & 26.2 & 0.09 & 28.3 & 0.09 & 27.5 & 0.10 & 5.1 & 1.4 \\
\hline US-born & 26.6 & 0.08 & 26.8 & 0.08 & 28.6 & 0.11 & 28.8 & 0.11 & 7.4 & 2.0 \\
\hline \multicolumn{11}{|l|}{ Puerto Rican } \\
\hline Recent immigrants & 25.5 & 0.19 & 25.5 & 0.18 & 27.3 & 0.37 & 27.5 & 0.33 & 6.9 & 1.8 \\
\hline Long-term immigrants & 26.9 & 0.12 & 26.1 & 0.12 & 28.1 & 0.21 & 27.6 & 0.20 & 4.7 & 1.3 \\
\hline US-born & 25.3 & 0.13 & 25.8 & 0.13 & 28.3 & 0.20 & 28.4 & 0.19 & 12.0 & 3.0 \\
\hline \multicolumn{11}{|l|}{ Cuban } \\
\hline Recent immigrants & 25.6 & 0.16 & 25.2 & 0.16 & 27.2 & 0.38 & 26.7 & 0.39 & 6.2 & 1.6 \\
\hline Long-term immigrants & 26.0 & 0.34 & 25.7 & 0.31 & 27.5 & 0.31 & 27.1 & 0.28 & 5.8 & 1.5 \\
\hline US-born & 25.3 & 0.28 & 25.8 & 0.27 & 27.2 & 0.43 & 27.7 & 0.42 & 7.2 & 1.8 \\
\hline
\end{tabular}


Table 3 continued

\begin{tabular}{|c|c|c|c|c|c|c|c|c|c|c|}
\hline \multirow[t]{3}{*}{ Covariates } & \multicolumn{4}{|c|}{$1992-1995(N=323,627)$} & \multicolumn{4}{|c|}{ 2003-2008 $(N=154,649)$} & \multirow{2}{*}{\multicolumn{2}{|c|}{$\frac{1992-2008}{\text { Increase in } \mathrm{BMI}^{\mathrm{b}}}$}} \\
\hline & \multicolumn{2}{|c|}{ Observed } & \multicolumn{2}{|c|}{ Adjusted $^{\mathrm{a}}$} & \multicolumn{2}{|c|}{ Observed } & \multicolumn{2}{|c|}{ Adjusted $^{\mathrm{a}}$} & & \\
\hline & BMI & SE & BMI & SE & BMI & SE & BMI & SE & $\%$ & Absolute \\
\hline \multicolumn{11}{|c|}{ Central and South Americans and other Hispanics } \\
\hline Recent immigrants & 24.7 & 0.11 & 24.8 & 0.09 & 26.0 & 0.12 & 26.0 & 0.13 & 5.1 & 1.3 \\
\hline Long-term immigrants & 25.5 & 0.10 & 25.1 & 0.10 & 27.6 & 0.13 & 27.0 & 0.14 & 8.2 & 2.1 \\
\hline US-born & 25.5 & 0.10 & 25.9 & 0.09 & 27.6 & 0.19 & 27.9 & 0.18 & 8.1 & 2.1 \\
\hline \multicolumn{11}{|l|}{ Gender } \\
\hline Male & 26.1 & 0.02 & 26.2 & 0.02 & 27.6 & 0.03 & 27.6 & 0.03 & 5.7 & 1.5 \\
\hline Female & 24.9 & 0.02 & 24.9 & 0.02 & 26.9 & 0.03 & 26.8 & 0.03 & 7.8 & 1.9 \\
\hline \multicolumn{11}{|c|}{ Education (years of school completed) } \\
\hline $0-8$ & 26.5 & 0.04 & 26.1 & 0.04 & 27.8 & 0.08 & 27.5 & 0.08 & 4.6 & 1.2 \\
\hline $9-11$ & 26.1 & 0.04 & 25.9 & 0.04 & 27.6 & 0.06 & 27.5 & 0.06 & 6.0 & 1.6 \\
\hline 12 & 25.7 & 0.02 & 25.6 & 0.02 & 27.7 & 0.04 & 27.5 & 0.04 & 7.8 & 2.0 \\
\hline $13-15$ & 25.2 & 0.03 & 25.5 & 0.02 & 27.4 & 0.04 & 27.5 & 0.04 & 8.7 & 2.2 \\
\hline $16+$ & 24.8 & 0.02 & 24.9 & 0.03 & 26.3 & 0.03 & 26.4 & 0.04 & 5.8 & 1.5 \\
\hline \multicolumn{11}{|l|}{ Family income (\$) } \\
\hline$<10,000$ & 26.0 & 0.09 & 26.1 & 0.08 & 27.6 & 0.12 & 27.9 & 0.12 & 6.2 & 1.6 \\
\hline $10,000-19,999$ & 26.0 & 0.04 & 26.0 & 0.04 & 27.4 & 0.07 & 27.6 & 0.07 & 5.7 & 1.5 \\
\hline $20,000-24,999$ & 25.8 & 0.04 & 25.8 & 0.04 & 27.4 & 0.09 & 27.5 & 0.09 & 6.2 & 1.6 \\
\hline $25,000-34,999$ & 25.7 & 0.04 & 25.7 & 0.04 & 27.4 & 0.07 & 27.4 & 0.07 & 6.8 & 1.7 \\
\hline $35,000-44,999$ & 25.6 & 0.03 & 25.6 & 0.03 & 27.6 & 0.07 & 27.4 & 0.07 & 7.6 & 1.9 \\
\hline $45,000-64,999$ & 25.5 & 0.03 & 25.5 & 0.03 & 27.4 & 0.06 & 27.3 & 0.06 & 7.5 & 1.9 \\
\hline $65,000+$ & 25.1 & 0.02 & 25.1 & 0.03 & 26.8 & 0.05 & 26.7 & 0.05 & 6.9 & 1.7 \\
\hline \multicolumn{11}{|c|}{ Poverty status (ratio of family income to poverty threshold) } \\
\hline$<100 \%$ & & & & & 27.6 & 0.08 & 27.8 & 0.06 & & \\
\hline $100-199 \%$ & & & & & 27.7 & 0.05 & 27.7 & 0.05 & & \\
\hline $200-299 \%$ & & & & & 27.5 & 0.05 & 27.4 & 0.05 & & \\
\hline $300-399 \%$ & & & & & 27.5 & 0.06 & 27.4 & 0.06 & & \\
\hline $400-499 \%$ & & & & & 27.2 & 0.06 & 27.1 & 0.06 & & \\
\hline$\geq 500 \%$ & & & & & 26.8 & 0.04 & 26.8 & 0.04 & & \\
\hline \multicolumn{11}{|l|}{ Occupation } \\
\hline Professional/managerial & 25.2 & 0.02 & 25.5 & 0.02 & 26.8 & 0.04 & 27.2 & 0.04 & 6.3 & 1.6 \\
\hline Sales/clerical/tech support & 25.1 & 0.02 & 25.4 & 0.02 & 27.1 & 0.04 & 27.3 & 0.04 & 8.3 & 2.1 \\
\hline Service & 25.7 & 0.04 & 25.6 & 0.03 & 27.5 & 0.06 & 27.4 & 0.06 & 7.1 & 1.8 \\
\hline Craft and repair & 26.2 & 0.03 & 25.4 & 0.04 & 27.8 & 0.05 & 27.1 & 0.05 & 6.1 & 1.6 \\
\hline Laborers & 26.2 & 0.03 & 25.6 & 0.03 & 28.3 & 0.07 & 27.7 & 0.07 & 8.1 & 2.1 \\
\hline Unemployed/not in LF & 25.5 & 0.02 & 25.6 & 0.03 & 26.4 & 0.10 & 27.1 & 0.10 & 3.6 & 0.9 \\
\hline
\end{tabular}

a Adjusted BMI was derived from fitted least square regression models that included survey year, age, gender, ethnic-immigrant status (or race/ ethnicity and length of immigration), marital status, family size, region of residence, education, occupation, and family income or poverty status b All percentage and absolute increases in BMI during 1992-2008 were statistically significantly different from $0(P<.01)$

in 2003-2008, the effect being significantly lower than the 0.19 point decrease in BMI in 1992-1995 $(P<.001)$.

Income gradients were steeper in 1992-1995 than in 2003-2006, with income disparities in prevalence, as measured by the summary indices, diminishing over time. During 2003-2006, those with family income $<\$ 10,000$ had $44 \%$ higher odds of obesity than those with income $\geq \$ 65,000$; the roughly comparable odds in 1992 1995 were $62 \%$ higher for those with family income $<\$ 7,000$ than for those with income $\geq \$ 50,000$. A $\$ 5,000$ increase in family income was associated with $7 \%$ $(\mathrm{OR}=0.93 ; 95 \% \mathrm{CI}=0.93-0.93)$ and $4 \%(\mathrm{OR}=0.96$; $95 \% \mathrm{CI}=0.96-0.96)$ lower odds of obesity and overweight, respectively in 1992-1995; in 2003-2006, the 
Table 4 Age-sex-year and covariate-adjusted odds of obesity (BMI $\geq 30$ ) and overweight (BMI $\geq 25)$ by ethnic-immigrant status (Chinese immigrants used as reference group), US adults aged 18+ years: The National Health Interview Survey, 2003-2008

\begin{tabular}{|c|c|c|c|c|c|c|c|c|c|c|c|c|}
\hline \multirow[t]{3}{*}{ Ethnic-immigrant group } & \multicolumn{3}{|c|}{ Obesity } & \multicolumn{3}{|c|}{ Obesity } & \multicolumn{3}{|c|}{ Overweight } & \multicolumn{3}{|c|}{ Overweight } \\
\hline & \multicolumn{3}{|c|}{$\begin{array}{l}\text { Age-sex-year adjusted } \\
\text { model }\end{array}$} & \multicolumn{3}{|c|}{$\begin{array}{l}\text { Covariate adjusted } \\
\text { model }^{\mathrm{a}}\end{array}$} & \multicolumn{3}{|c|}{$\begin{array}{l}\text { Age-sex-year adjusted } \\
\text { model }\end{array}$} & \multicolumn{3}{|c|}{$\begin{array}{l}\text { Covariate adjusted } \\
\text { model }^{\mathrm{a}}\end{array}$} \\
\hline & OR & \multicolumn{2}{|c|}{$95 \% \mathrm{CI}$} & OR & \multicolumn{2}{|c|}{$95 \% \mathrm{CI}$} & OR & \multicolumn{2}{|c|}{$95 \% \mathrm{CI}$} & OR & \multicolumn{2}{|c|}{$95 \% \mathrm{CI}$} \\
\hline \multicolumn{13}{|l|}{ Non-Hispanic White } \\
\hline Recent immigrants & 4.50 & 2.83 & 7.18 & 4.33 & 2.71 & 6.91 & 3.78 & 2.99 & 4.79 & 3.70 & 2.92 & 4.69 \\
\hline Long-term immigrants & 8.30 & 5.34 & 12.90 & 7.81 & 5.02 & 12.16 & 5.04 & 4.06 & 6.26 & 4.78 & 3.83 & 5.96 \\
\hline US-born & 11.91 & 7.75 & 18.31 & 10.46 & 6.77 & 16.14 & 5.87 & 4.82 & 7.14 & 5.27 & 4.31 & 6.44 \\
\hline \multicolumn{13}{|l|}{ Non-Hispanic Black } \\
\hline Recent immigrants & 8.39 & 5.18 & 13.57 & 6.73 & 4.13 & 10.98 & 5.01 & 3.87 & 6.47 & 4.37 & 3.37 & 5.67 \\
\hline Long-term immigrants & 11.77 & 7.44 & 18.62 & 9.92 & 6.25 & 15.76 & 7.85 & 6.05 & 10.19 & 7.10 & 5.45 & 9.25 \\
\hline US-born & 21.30 & 13.88 & 32.68 & 16.74 & 10.86 & 25.80 & 10.30 & 8.42 & 12.60 & 9.05 & 7.36 & 11.12 \\
\hline American Indian/Alaska Native & 24.11 & 15.11 & 38.48 & 18.93 & 11.82 & 30.31 & 9.74 & 7.40 & 12.83 & 8.33 & 6.31 & 11.00 \\
\hline \multicolumn{13}{|l|}{ Chinese } \\
\hline Immigrants (all) & 1.00 & \multicolumn{2}{|c|}{ Reference } & 1.00 & \multicolumn{2}{|c|}{ Reference } & 1.00 & \multicolumn{2}{|c|}{ Reference } & 1.00 & \multicolumn{2}{|c|}{ Reference } \\
\hline US-born & 3.59 & 1.76 & 7.34 & 4.16 & 2.02 & 8.59 & 3.00 & 2.06 & 4.37 & 3.37 & 2.30 & 4.93 \\
\hline \multicolumn{13}{|l|}{ Filipino } \\
\hline Recent immigrants & 3.10 & 1.59 & 6.02 & 3.03 & 1.57 & 5.86 & 2.75 & 2.01 & 3.74 & 2.69 & 1.97 & 3.66 \\
\hline Long-term immigrants & 4.79 & 2.91 & 7.91 & 4.68 & 2.83 & 7.73 & 3.22 & 2.41 & 4.29 & 3.12 & 2.32 & 4.20 \\
\hline US-born & 9.54 & 5.68 & 16.00 & 8.87 & 5.28 & 14.88 & 5.55 & 4.00 & 7.69 & 5.41 & 3.86 & 7.58 \\
\hline \multicolumn{13}{|l|}{ Asian Indian } \\
\hline Recent immigrants & 2.34 & 1.35 & 4.06 & 2.43 & 1.40 & 4.22 & 2.61 & 2.01 & 3.40 & 2.69 & 2.07 & 3.50 \\
\hline Long-term immigrants/US-born & 3.34 & 1.93 & 5.77 & 3.43 & 1.98 & 5.94 & 3.05 & 2.24 & 4.15 & 3.11 & 2.28 & 4.24 \\
\hline Other Asian and Pacific Islanders & & & & & & & & & & & & \\
\hline Recent immigrants & 1.57 & 0.85 & 2.91 & 1.41 & 0.76 & 2.60 & 1.27 & 0.93 & 1.74 & 1.22 & 0.89 & 1.68 \\
\hline Long-term immigrants & 2.62 & 1.56 & 4.42 & 2.31 & 1.37 & 3.90 & 1.87 & 1.48 & 2.37 & 1.74 & 1.37 & 2.21 \\
\hline US-born & 8.81 & 5.19 & 14.93 & 8.62 & 5.12 & 14.51 & 4.33 & 3.13 & 6.01 & 4.29 & 3.08 & 5.97 \\
\hline Mexican & & & & & & & & & & & & \\
\hline Recent immigrants & 9.81 & 6.34 & 15.17 & 6.89 & 4.44 & 10.71 & 7.70 & 6.26 & 9.48 & 6.26 & 5.07 & 7.73 \\
\hline Long-term immigrants & 15.15 & 9.84 & 23.31 & 10.82 & 7.01 & 16.71 & 10.32 & 8.32 & 12.80 & 8.42 & 6.77 & 10.48 \\
\hline US-born & 21.43 & 13.78 & 33.32 & 17.10 & 10.99 & 26.63 & 11.09 & 9.02 & 13.63 & 9.54 & 7.73 & 11.76 \\
\hline Puerto Rican & & & & & & & & & & & & \\
\hline Recent immigrants & 15.85 & 9.45 & 26.59 & 12.31 & 7.28 & 20.80 & 7.28 & 5.21 & 10.17 & 6.25 & 4.46 & 8.77 \\
\hline Long-term immigrants & 16.76 & 10.65 & 26.38 & 12.88 & 8.14 & 20.36 & 9.26 & 7.16 & 11.97 & 7.98 & 6.12 & 10.39 \\
\hline US-born & 17.30 & 11.04 & 27.08 & 13.82 & 8.79 & 21.72 & 9.18 & 7.21 & 11.68 & 7.91 & 6.19 & 10.10 \\
\hline Cuban & & & & & & & & & & & & \\
\hline Recent immigrants & 10.01 & 5.62 & 17.81 & 7.48 & 4.21 & 13.30 & 7.04 & 4.68 & 10.60 & 5.91 & 3.91 & 8.94 \\
\hline Long-term immigrants & 10.97 & 6.83 & 17.60 & 8.76 & 5.44 & 14.12 & 6.35 & 4.77 & 8.46 & 5.50 & 4.14 & 7.32 \\
\hline US-born & 13.28 & 7.87 & 22.39 & 11.78 & 6.96 & 19.94 & 6.40 & 4.54 & 9.03 & 5.88 & 4.17 & 8.30 \\
\hline Central and South Americans and & other $\mathrm{H}$ & panics & & & & & & & & & & \\
\hline Recent immigrants & 6.60 & 4.17 & 10.46 & 5.05 & 3.17 & 8.03 & 5.35 & 4.26 & 6.72 & 4.53 & 3.59 & 5.72 \\
\hline Long-term immigrants & 11.43 & 7.28 & 17.95 & 8.75 & 5.55 & 13.79 & 8.15 & 6.50 & 10.22 & 6.95 & 5.52 & 8.75 \\
\hline US-born & 15.64 & 10.21 & 23.94 & 13.52 & 8.79 & 20.79 & 8.65 & 6.91 & 10.83 & 7.88 & 6.27 & 9.91 \\
\hline
\end{tabular}

${ }^{a}$ Adjusted for survey year, age, gender, marital status, family size, region of residence, education, occupation, and poverty status

corresponding odds ratios were smaller: $0.97 \quad(95 \%$ $\mathrm{CI}=0.97-0.98)$ for obesity and $0.99(95 \% \mathrm{CI}=0.98$ $0.99)$ for overweight. A $\$ 5,000$ increase in family income was associated with a 0.08 point decrease in BMI in $2003-$ 2006, the effect being significantly lower than the 0.14 point decrease in BMI in 1992-1995 $(P<.001)$. 
The obesity prevalence for individuals in sales occupations quadrupled and for those in other occupations tripled between 1976 and 2003-2008. In 2003-2008, after adjusting for education, income, and other demographic factors, service workers and laborers had 7 and $21 \%$ higher odds of obesity than those employed in professional/ managerial occupations. Although observed occupational inequalities in obesity were substantial, most of the occupational effects were accounted for by education and income differences.

After adjusting for ethnicity and socioeconomic factors, physical inactivity was associated with $54 \%$ higher odds of obesity $(\mathrm{OR}=1.54 ; 95 \% \quad \mathrm{CI}=1.46-1.62)$ and $36 \%$ higher odds of overweight $(\mathrm{OR}=1.36$; $95 \% \mathrm{CI}=1.30$ 1.42 ) in 2003-2008 (data from the full model not shown).

\section{Discussion}

Race/ethnicity, immigrant status, and social class have long been considered three of the most important axes of health and social stratification [1, 2, 21]. Health and social inequalities by these factors remain quite marked in the contemporary US [1, 4, 12, 20, 21]. Our study examined long-term trends and inequalities in obesity and overweight prevalence among adults from a wide range of social class and immigrants groups, using nationally representative annual cross-sectional samples of the US population. Although immigrant differentials in adult obesity have been examined previously in the US [4, 11, 25], immigrant disparities in obesity across all of the major racial/ethnic groups had not been explored. Furthermore, previous national studies had not examined a wide range of socioeconomic differentials in adult obesity using different socioeconomic measures, such as education, occupation, income, and poverty status [1, 5-7].

Decreasing social class gradients in obesity shown here are consistent with those reported for adult obesity trends in Canada and England, where men and women in higher income or social class groups, despite having lower prevalence than their counterparts from lower income groups, have experienced faster increases in their obesity rates [26-28]. Diminishing socioeconomic differentials in US adult obesity prevalence, along with steeper increases in obesity among higher socioeconomic groups over time, were also found using measured height and weight data from the NHANES $[1,5,6]$. Socioeconomic trends in US adult obesity rates, however, differ from US childhood obesity trends-which indicate rising social inequalities in prevalence during this decade [16]. Declining physical activity levels and increases in total energy intake may have contributed to rising trends in adult obesity [1, 29]. In analyses not shown here, we found that although increased PA was associated with reduced obesity risks in both immigrants and natives, adjusting for PA levels had little impact on the magnitude of ethnic-immigrant differentials in adult obesity. Indeed, because immigrants had higher inactivity levels, adjusting for PA only widened immigrant differentials in obesity. Although PA did partly account for socioeconomic differences in obesity risks during 2003-2008, the extent to which social class trends in physical inactivity and sedentary activities account for obesity trends is not known due to lack of temporal data.

Ethnic-immigrant and social class differences in dietary factors in Appendix Table 5 might provide some insights into understanding the obesity differentials shown here. Immigrants in each racial/ethnic group have significantly lower total calorie and fat intake than the US-born. Moreover, immigrants' likelihood of excess calorie and fat intake increases with increasing length of residence in the US. Contrary to expectation, the NHANES data show lower total calorie and fat intake among adults in lower SES groups. However, studies have found higher consumption of lower-quality diets and energy-dense foods and lower intakes of fruits and vegetables among lower SES groups [30, 31]. Income or education differences in energy density, fruit and vegetable intake, and other dietary outcomes have persisted or narrowed over time, with individuals in higher socioeconomic groups losing their relative advantage in diet quality in more recent times [30]. These dietary trends appear to coincide with the social class trends in obesity reported here. Future studies need to directly assess the significance of dietary influences in explaining temporal changes in obesity risks and differentials between immigrant and social class groups.

Positive immigrant selectivity in health, education, skills, and ambition has been suggested as a possible explanation for lower obesity risks among immigrants $[4,9]$. Those migrating to the US in recent decades have come predominantly from Latin America and Asia, who tend to be healthier than those who remain in their countries of origin. Given the US immigration laws of the past four decades, most immigrants are chosen rather than randomly self-selected based primarily on their skill criteria [4]. Asian immigrants, in particular, are a highly selective group with relatively high socioeconomic attainment levels as noted in Fig. 2 [4].

Immigrant patterns in obesity shown here are consistent with those observed for other health indicators, including smoking, breastfeeding, infant mortality, low birthweight, morbidity, mortality, and life expectancy [4, 9, 11, 32]. Immigrants have a significant advantage over the US-born in most health and behavioral outcomes, which tends to decrease with increasing acculturation levels or length of residence in the US [4, 9, 11, 32]. Consistent with previous 
Table 5 Nutritional Characteristics by ethnic-immigrant status and socioeconomic factors for US adults aged 20 years and older: The 20012006 National Health and Nutrition Examination Survey (NHANES)

\begin{tabular}{|c|c|c|c|c|c|c|c|c|c|c|c|c|c|c|c|c|c|c|}
\hline \multirow[t]{3}{*}{ Characteristic } & \multicolumn{4}{|c|}{ Energy intake in kcals } & \multicolumn{5}{|c|}{ Calorie intake $\geq 3500$} & \multicolumn{4}{|c|}{ Fat intake in $g$} & \multicolumn{5}{|c|}{ Fat intake $\geq 120 \mathrm{~g}$} \\
\hline & \multicolumn{2}{|c|}{ Observed } & \multicolumn{2}{|c|}{ Adjusted $^{\mathrm{a}}$} & \multicolumn{2}{|c|}{ Prevalence } & \multicolumn{3}{|c|}{ Adjusted $^{\mathrm{a}}$} & \multicolumn{2}{|c|}{ Observed } & \multicolumn{2}{|c|}{ Adjusted $^{\mathrm{a}}$} & \multicolumn{2}{|c|}{ Prevalence } & \multicolumn{3}{|c|}{ Adjusted $^{\mathrm{a}}$} \\
\hline & Mean & SE & Mean & SE & $\%$ & SE & OR & $95 \%$ & & Mean & SE & Mean & SE & $\%$ & SE & OR & $95 \%$ & \\
\hline \multicolumn{19}{|c|}{ Duration of residence in the US (years) ${ }^{b}$} \\
\hline$<5$ & 2,002 & 67 & 1,895 & 58 & 7.0 & 1.6 & 0.49 & 0.26 & 0.93 & 64 & 3 & 63 & 3 & 7.6 & 2.6 & 0.29 & 0.14 & 0.57 \\
\hline $5-9$ & 2,194 & 110 & 2,092 & 100 & 9.5 & 2.3 & 0.69 & 0.38 & 1.27 & 78 & 5 & 77 & 5 & 12.9 & 3.2 & 0.55 & 0.30 & 1.00 \\
\hline $10-19$ & 2,161 & 102 & 2,052 & 101 & 9.4 & 2.3 & 0.72 & 0.36 & 1.42 & 78 & 5 & 75 & 5 & 13.8 & 2.8 & 0.55 & 0.31 & 1.00 \\
\hline $20+$ & 2,098 & 67 & 2,154 & 78 & 9.7 & 2.0 & 1.09 & 0.59 & 2.02 & 77 & 4 & 79 & 4 & 12.1 & 1.7 & 0.61 & 0.38 & 0.99 \\
\hline US-born & 2,235 & 30 & 2,242 & 30 & 10.4 & 0.6 & 1.00 & \multicolumn{2}{|c|}{ Reference } & 86 & 1 & 86 & 1 & 18.2 & 1.2 & 1.00 & \multicolumn{2}{|c|}{ Reference } \\
\hline \multicolumn{19}{|c|}{ Non-Hispanic White } \\
\hline US-born & 2,248 & 15 & 2,265 & 15 & 11.2 & 0.4 & 1.00 & \multicolumn{2}{|c|}{ Reference } & 86 & 1 & 86 & 1 & 18.5 & 0.6 & 1.00 & \multicolumn{2}{|c|}{ Reference } \\
\hline Immigrant & 2,177 & 62 & 2,180 & 55 & 10.1 & 1.9 & 0.82 & 0.53 & 1.29 & 81 & 3 & 81 & 3 & 14.4 & 2.0 & 0.70 & 0.50 & 0.98 \\
\hline \multicolumn{19}{|c|}{ Non-Hispanic Black } \\
\hline US-born & 2,181 & 24 & 2,186 & 21 & 11.3 & 0.8 & 0.94 & 0.79 & 1.11 & 83 & 1 & 84 & 1 & 17.3 & 0.8 & 0.93 & 0.83 & 1.06 \\
\hline Immigrant & 1,994 & 62 & 1,921 & 67 & 4.1 & 1.6 & 0.26 & 0.11 & 0.63 & 67 & 3 & 65 & 3 & 6.3 & 1.5 & 0.24 & 0.13 & 0.42 \\
\hline \multicolumn{19}{|c|}{ Mexican American } \\
\hline US-born & 2,303 & 41 & 2,250 & 41 & 13.7 & 1.4 & 1.03 & 0.77 & 1.38 & 88 & 2 & 87 & 2 & 19.2 & 1.6 & 0.97 & 0.76 & 1.25 \\
\hline Immigrant & 2,253 & 28 & 2,103 & 32 & 10.7 & 1.0 & 0.51 & 0.38 & 0.69 & 77 & 1 & 73 & 2 & 13.0 & 1.1 & 0.49 & 0.37 & 0.63 \\
\hline \multicolumn{19}{|l|}{ Other Hispanic } \\
\hline US-born & 2,100 & 74 & 2,106 & 55 & 4.7 & 1.5 & 0.34 & 0.18 & 0.65 & 78 & 4 & 79 & 3 & 14.7 & 2.9 & 0.81 & 0.50 & 1.32 \\
\hline Immigrant & 2,076 & 65 & 2,017 & 64 & 6.4 & 1.8 & 0.40 & 0.20 & 0.78 & 73 & 3 & 72 & 3 & 10.9 & 2.2 & 0.45 & 0.28 & 0.71 \\
\hline All other ethni & groups & & & & & & & & & & & & & & & & & \\
\hline US-born & 2,285 & 65 & 2,226 & 62 & 10.0 & 1.9 & 0.72 & 0.48 & 1.07 & 87 & 3 & 85 & 2 & 17.2 & 2.3 & 0.81 & 0.58 & 1.13 \\
\hline Immigrant & 1,939 & 43 & 1,945 & 45 & 4.7 & 1.1 & 0.37 & 0.22 & 0.63 & 65 & 2 & 65 & 2 & 5.8 & 1.3 & 0.25 & 0.15 & 0.42 \\
\hline Education (yea & rs of sch & $\mathrm{OOl} \mathrm{co}$ & mpleted & & & & & & & & & & & & & & & \\
\hline$<12$ & 2,106 & 25 & 2,186 & 26 & 10.0 & 0.7 & 1.00 & Refer & ence & 77 & 1 & 81 & 1 & 13.4 & 0.7 & 1.00 & Refere & nce \\
\hline 12 & 2,260 & 21 & 2,260 & 17 & 12.1 & 0.7 & 0.97 & 0.77 & 1.22 & 86 & 1 & 86 & 1 & 18.9 & 0.9 & 1.21 & 1.01 & 1.44 \\
\hline $13+$ & 2,245 & 14 & 2,218 & 15 & 10.4 & 0.4 & 0.83 & 0.66 & 1.04 & 85 & 1 & 84 & 1 & 17.7 & 0.6 & 1.09 & 0.93 & 1.28 \\
\hline Poverty status & (ratio of & family & income & to po & rerty th & eshol & & & & & & & & & & & & \\
\hline$<100 \%$ & 2,188 & 24 & 2,205 & 25 & 10.8 & 0.8 & 1.00 & Refer & ence & 80 & 1 & 83 & 1 & 16.3 & 0.9 & 1.00 & Refere & nce \\
\hline $100-199 \%$ & 2,149 & 25 & 2,211 & 23 & 10.3 & 0.7 & 1.06 & 0.82 & 1.36 & 80 & 1 & 84 & 1 & 14.7 & 0.8 & 0.92 & 0.74 & 1.13 \\
\hline $200-299 \%$ & 2,186 & 27 & 2,185 & 23 & 11.3 & 0.9 & 1.09 & 0.83 & 1.44 & 83 & 1 & 83 & 1 & 17.8 & 1.4 & 1.00 & 0.80 & 1.27 \\
\hline $300-399 \%$ & 2,263 & 35 & 2,223 & 33 & 9.8 & 0.9 & 0.82 & 0.62 & 1.08 & 85 & 2 & 83 & 2 & 16.7 & 1.2 & 0.82 & 0.66 & 1.04 \\
\hline $400-499 \%$ & 2,260 & 26 & 2,223 & 28 & 10.2 & 0.8 & 0.88 & 0.68 & 1.13 & 87 & 1 & 85 & 1 & 18.5 & 1.2 & 0.94 & 0.76 & 1.16 \\
\hline$\geq 500 \%$ & 2,295 & 22 & 2,255 & 21 & 11.7 & 0.9 & 1.05 & 0.80 & 1.37 & 88 & 1 & 85 & 1 & 19.8 & 0.8 & 0.98 & 0.79 & 1.20 \\
\hline
\end{tabular}

${ }^{a}$ Adjusted by weighted least squares or logistic regression for time period, age, gender, ethnic-immigrant status (or race/ethnicity and length of immigration), marital status, education, and poverty status

${ }^{b}$ Duration of residence in the US was available only for the 2005-2006 NHANES

research on acculturation and obesity risks among US and Canadian immigrants[11, 25, 33, 34], our study showed increasing obesity rates with increasing duration of US residence in both 1992-1995 and 2003-2008.

This study has some limitations. Obesity and overweight prevalence estimates from NHIS are derived from self-reported height and weight data, which may underestimate the actual prevalence among ethnic-immigrant and social class groups [1, 26]. In 2007-2008, for example, $26.8 \%$ of US adults aged $\geq 18$ were classified as obese based on the NHIS data, whereas the NHANES prevalence was $33.0 \%$ [35]. However, the NHANES with its much smaller sample size does not permit detailed examinations of ethnic, immigrant, and socioeconomic disparities in obesity such as those shown here. Second, because of the cross-sectional nature of the NHIS, the obesity impacts of socioeconomic variables and PA may have been misestimated. Third, dietary information in the 
NHIS is lacking, and data on immigration and acculturation are limited. The survey does not collect information on legal status of immigrants as well as more direct measures of acculturation such as ethnic-cultural identity, social networks, and dietary preference [4, 9, 11, 33]. Finally, we did not examine if ethnic-immigrant and social class trends in obesity differed by gender; this should be examined in future studies.

In conclusion, continued immigrant and socioeconomic disparities in prevalence will likely have substantial impacts on future obesity trends in the US. Immigrants in each racial/ethnic group generally had lower obesity risks than their US-born counterparts, with immigrants' obesity risks increasing with increasing length of stay in the US. Considerable heterogeneity in risk was observed, with US-born blacks, Mexicans, blacks, Puerto Ricans, and American Indians having 10-14 times higher obesity prevalence than Chinese immigrants. Barring US-born and foreign-born Chinese and Asian Indians, an average American was likely to be overweight. Nearly two-thirds of all US-born adults were obese or overweight. The overall obesity and overweight prevalence for US adults and an overweight prevalence of $70 \%$ or higher for some groups such as US-born blacks, American Indians, Mexican immigrants, and Puerto Rican immigrants rank among the highest in the world [19, 36, 37]. Clearly, the presence of such large ethnic-immigrant and social class disparities is a major reason for America's unfavorable international standing in obesity. Continued monitoring of disparities in obesity prevalence among immigrant and social class groups is, therefore, essential in tracking progress towards achieving the national goal of eliminating health inequalities $[1,2]$.

\section{Conflict of interest statement None}

Open Access This article is distributed under the terms of the Creative Commons Attribution Noncommercial License which permits any noncommercial use, distribution, and reproduction in any medium, provided the original author(s) and source are credited.

\section{Appendix}

\section{See Table 5.}

\section{References}

1. National Center for Health Statistics. (2010). Health, United States, 2009 with special feature on medical technology. Hyattsville, MD: US Department of Health and Human Services.

2. US Department of Health, Human Services. (2000). Healthy People 2010: Understanding and improving health (2nd ed.). Washington, DC: US Government Printing Office.
3. Flegal, K. M., Carroll, M. D., Ogden, C. L., \& Curtin, L. R. (2010). Prevalence and trends in obesity among US adults, 19992008. JAMA, 303(3), 235-241.

4. Singh, G. K., \& Hiatt, R. A. (2006). Trends and disparities in socioeconomic and behavioral characteristics, life expectancy, and cause-specific mortality of native-born and foreign-born populations in the United States, 1979-2003. International Journal of Epidemiology, 35(4), 903-919.

5. Wang, Y., \& Beydoun, M. A. (2007). The obesity epidemic in the United States-gender, age, socioeconomic, racial/ethnic, and geographic characteristics: A systematic review and metaregression analysis. Epidemiologic Reviews, 29, 6-28.

6. Zhang, Q., \& Wang, Y. (2004). Trends in the association between obesity and socioeconomic status in U.S. adults: 1971-2000. Obesity Research, 12, 1622-1632.

7. Caban, A. J., Lee, D. J., Fleming, L. E., et al. (2005). Obesity in US workers: The National Health Interview Survey, 1986-2002. American Journal of Public Health, 95(9), 1614-1622.

8. Larsen L. J. (2003). The foreign-born population in the United States: 2003. Current Population Reports, P20-551. Washington, DC: US Census Bureau.

9. Singh, G. K., \& Miller, B. A. (2004). Health, life expectancy, and mortality patterns among immigrant populations in the United States. Canadian Journal of Public Health, 95(3), I14-I21.

10. US Census Bureau. The 2008 American Community Survey. Washington, DC: US Census Bureau; 2009. Available at http:// factfinder.census.gov/servlet/ADPTable?_bm=y\&-geo_id=01000 US\&-ds_name=ACS_2008_1YR_G00_\&-_lang=en\&-_caller= geoselect\&-format $=$. Accessed 6 November 2009.

11. Singh, G. K., \& Siahpush, M. (2002). Ethnic-immigrant differentials in health behaviors, morbidity, and cause-specific mortality in the United States: An analysis of two national data bases. Human Biology, 74(1), 83-109.

12. Singh, G. K., \& Siahpush, M. (2006). Widening socioeconomic inequalities in US life expectancy, 1980-2000. International Journal of Epidemiology, 35(4), 969-979.

13. Singh, G. K. (2003). Area deprivation and widening inequalities in US mortality, 1969-1998. American Journal of Public Health, 93(7), 1137-1143.

14. Singh, G. K., \& Siahpush, M. (2002). Increasing inequalities in all-cause and cardiovascular mortality among US adults aged 2564 years by area socioeconomic status, 1969-1998. International Journal of Epidemiology, 31(3), 600-613.

15. Singh, G. K., \& Kogan, M. D. (2007). Widening socioeconomic disparities in US childhood mortality. American Journal of Public Health, 97(9), 1658-1665.

16. Singh, G. K., Siahpush, M., \& Kogan, M. D. (2010). Rising social inequalities in US childhood obesity, 2003-2007. Annals of Epidemiology, 20(1), 40-52.

17. Pleis, J. R., Lucas, J. W., \& Ward, B. W. (2009). Summary health statistics for U.S. adults: National Health Interview Survey 2008. Vital Health Statistics, 10(242), 1-157.

18. National Center for Health Statistics. The National Health Interview Survey, Questionnaires, Datasets, and Related Documentation: 1976 and 1991-2008 Public Use Data Files. Hyattsville, MD: US Department of Health and Human Services; 2009. Available at: http://www.cdc.gov/nchs/nhis/nhis_questionnaires.htm (Accessed January 6, 2010).

19. Branca F., Nikogosian H., \& Lobstein T. (eds).(2007). The Challenge of Obesity in the WHO European Region and the Strategies for Response. Copenhagen, Denmark:WHO Regional Office for Europe.

20. US Census Bureau.(2009). Statistical abstract of the United States, 2010. (129th ed.) Washington, DC: US Government Printing Office. 
21. Singh, G. K., \& Kposowa, A. J. (1996). Occupation-specific earnings attainment of Asian Indians and Whites in the United States: Gender and nativity differentials across class strata. Applied Behavioral Science Review, 4(2), 137-175.

22. SUDAAN. (2005). Software for the Statistical Analysis of Correlated Data, Release 9.0.1. Research Triangle Park, NC: Research Triangle Institute.

23. Pearcy, J. N., \& Keppel, K. G. (2002). A summary measure of health disparity. Public Health Reports, 117, 273-280.

24. Siahpush, M., English, D. R., \& Powles, J. (2006). The contribution of smoking to socio-economic differentials in mortality: Results from the Melbourne Collaborative Cohort Study, Australia. Journal of Epidemiology and Community Health, 60, 1077-1079.

25. Goel, M. S., McCarthy, E. P., Philips, R. S., \& Wee, C. C. (2004). Obesity among US immigrant subgroups by duration of residence. JAMA, 292(23), 2860-2867.

26. Shields, M., \& Tjepkema, M. (2006). Trends in adult obesity. Health Reports, 17(3), 53-59.

27. Department of Health. (2009). Tackling health inequalities: 10 years On-a review of developments in tackling health inequalities in England over the last 10 years. London, UK: Department of Health.

28. Zaninotto, P., Head, J., Stamatakis, E., Wardle, H., \& Mindell, J. (2009). Trends in obesity among adults in England from 1993 to 2004 by age and social class and projections of prevalence to 2012 . Journal of Epidemiology and Community Health, 63, 140-146.

29. Brownson, R. C., Boehmer, T. K., \& Lake, D. A. (2005). Declining rates of physical activity in the United States: What are the contributors? Annual Review of Public Health, 26, 421-443.
30. Kant, A. K., \& Graubard, B. I. (2005). Secular trends in the association of socio-economic position with self-reported dietary attributes and biomarkers in the US population: National Health and Nutrition Examination Survey (NHANES) 1971-1975 to NHANES 1999-2002. Public Health Nutrition, 10(2), 158-167.

31. Darmon, N., \& Drewnowski, A. (2008). Does social class predict diet quality? American Journal of Clinical Nutrition, 87(5), 1107-1117.

32. Singh, G. K., Kogan, M. D., \& Dee, D. L. (2007). Nativity/ immigrant status, race/ethnicity, and socioeconomic determinants of breastfeeding initiation and duration in the United States, 2003. Pediatrics, 119(1), S38-S46.

33. Perez, C. E. (2002). Health status and health behavior among immigrants. Health Reports, 13(Suppl), 1-12.

34. Tremblay, M. S., Perez, C. E., Ardern, C. I., Bryan, S. N., \& Katzmarzyk, P. T. (2005). Obesity, overweight and ethnicity. Health Reports, 16(4), 23-34.

35. National Center for Health Statistics. (2009). The National Health and Nutrition Examination Survey (NHANES), 1999-2008 Public Use Data Files. Hyattsville, MD: US Department of Health and Human Services; Available at: http://www.cdc.gov/nchs/nhanes/ nhanes_questionnaires.htm (Accessed October 9, 2009).

36. Kuipers, Y. M. (2009). Focusing on Obesity through a Health Equity Lens. Brussels, Belgium: EuroHealthNet.

37. Balkau, B., Deanfield, J. E., Despres, J. P., et al. (2007). International Day for the Evaluation of Abdominal Obesity (IDEA): a study of waist circumference, cardiovascular disease, and diabetes mellitus in 168, 000 primary care patients in 63 countries. Circulation, 116, 1942-1951. 